\title{
Aggressive Orders and the Resiliency of a Limit Order Market *
}

\author{
HANS DEGRYSE ${ }^{1,2}$, FRANK DE JONG $^{3}$, MAARTEN VAN RAVENSWAAIJ ${ }^{4}$ \\ and GUNTHER WUYTS ${ }^{1,5}$ \\ ${ }^{1}$ Department of Economics, Katholieke Universiteit Leuven; ${ }^{2}$ CentER, Tilburg; ${ }^{3}$ Finance Group, \\ University of Amsterdam; ${ }^{4}$ SNS Asset Management, 's Hertogenbosch; ${ }^{5}$ National Bank of Belgium, \\ Research Department, Brussels
}

\begin{abstract}
We analyze the resiliency of a pure limit order market by investigating the limit order book (bid and ask prices, spreads, depth and duration), order flow and transaction prices in a window of best limit updates and transactions around aggressive orders (orders that move prices). We find strong persistence in the submission of aggressive orders. Aggressive orders take place when spreads and depths are relatively low, and they induce bid and ask prices to be persistently different after the shock. Depth and spread remain also higher than just before the order, but do return to their initial level within 20 best limit updates after the shock. Relative to the sample average, depths stay around their mean before and after aggressive orders, whereas spreads return to their mean after about twenty best limit updates. The initial price impact of the aggressive order is partly reversed in the subsequent transactions. However, the aggressive order produces a long-term effect as prices show a tendency to return slowly to the price of the aggressive order.
\end{abstract}

\section{Introduction}

Throughout the world, there exists a wide diversity of trading systems. In recent surveys of equity markets, Domowitz and Steil (1999) observe that many new trading systems and recently restructured markets apply a limit order design, and Jain (2002) shows that about half of the stock markets throughout the world are organized as a pure limit order market. In such a trading structure, liquidity is provided by a limit order book, where unfilled limit orders are stored, waiting for possible execution. Given the recent upswing in this type of market, an important question is how efficiently limit order markets operate. A major aspect of the performance of a trading mechanism is its liquidity. In a liquid market, traders should not be concerned about the time in between the submission and the execution of their orders, nor about the price impact or execution costs. Harris

* We thank Theo Nijman, Erik Theissen, Rob van den Goorbergh, Josef Zechner (editor) and an anonymous referee for valuable comments on an earlier draft as well as seminar participants at the EEA-conference in Venice, the CFS Conference on Market Design in Eltville, CORE, Leuven and Tilburg. The first and last authors gratefully acknowledge financial assistance from FWO-Flanders under contract G.0333. 
(1990) distinguishes four dimensions that are associated with liquidity: width (the bid-ask spread for a given number of shares), depth, immediacy and resiliency. The literature has already studied extensively the three first characteristics of liquidity (for an overview, see Biais et al. (2002)). A characteristic of liquidity, however, that has received little attention in empirical research so far is resiliency, although Stigler (1964) already stressed its importance. Exceptions are Bhattacharya and Spiegel (1998) who study trading suspensions on the NYSE and Coppejans et al. (2003), who investigate the resiliency of the Swedish stock index futures market (OMX).

The resiliency of a limit order market is the main topic of our paper. Harris (1990) defines resiliency as "how quickly prices revert to former levels after they change in response to large order flow imbalances initiated by uninformed traders". In a dealership market, a market maker has an obligation to assure the liquidity of a market in all circumstances, which is cited frequently as one of the important reasons for their presence. In contrast to this, in a limit order market, the lack of designated market makers who make the market continuously may cause illiquidity (and lack of resiliency) in some periods. Depending on the willingness of investors to provide liquidity as if they are market makers, liquidity will vary over time and may even be absent at certain times. The question of resiliency is therefore very relevant particularly for a limit order market. As in Foucault et al. (2003), we apply a broader definition of resiliency and define it as the speed of recovery of the market (in terms of prices, depth and spreads) after a relatively large shock, defined as a trade that increases the bid-ask spread. A natural period for studying resiliency therefore is the time span after aggressive orders, defined as orders that increase the bid-ask spread. We relate resiliency to the state of the market (characteristics at the time of the aggressive order as well as the sample average) and firm characteristics such as market capitalization and tick size. Theoretical work on sequential price formation helps us in formulating expectations about order flow behaviour after aggressive orders. For example, Parlour (1998) shows that buy and sell orders inducing a multiple-tick spread are more likely to be followed by orders leading to an increase in ask and bid, respectively. Theory suggests as well that the order submission behaviour - the choice between market orders and limit orders and their aggressiveness - also depends on the tick size and the stock's market capitalization. Cordella and Foucault (1999) show that resiliency is a function of tick size. Dealers in markets with larger tick size have stronger incentives to faster quote the competitive price, as this allows them to secure a larger profit. Foucault, Kadan and Kandel (2003) find that imposing a positive tick size improves the resiliency of a limit order market, as compared to the case of a zero minimum price variation. More details about these theories are in section 2 of this paper.

Our empirical analysis focuses on an eminent example of a limit order market, namely the Paris Bourse (nowadays Euronext Paris). We study resiliency in two ways. We focus on order flow around aggressive orders. We do this by looking at the limit order book and identifying the impact of an aggressive order on best ask 
and bid prices, depth and spread. We also deal with the impact of aggressive orders on transaction prices. We select 20 stocks from the more actively traded securities on the Paris Bourse. These stocks differ in market capitalization and in tick size, which allows us to study the relation between these characteristics and resiliency.

First, we document patterns in the order flow around aggressive orders. Several aspects of the impact of an aggressive order are studied. We examine the relation between aggressive orders and the state of the limit order book. We look at the frequency of the different order types. Also, using conditional probabilities, we look at the order types following an aggressive order. In this way, we can determine whether and how quickly liquidity after an aggressive order is restored. We extend the analysis of Biais et al. (1995), henceforth BHS95, by not only studying the next order, but also subsequent orders.

Secondly, we investigate the market impact of aggressive orders. We achieve this using an event study type of approach in which we inspect both limit order book variables and transaction prices around aggressive orders. To analyze the behaviour of limit order book variables, we construct a window of 10 updates of the best limits before and 20 updates after the aggressive order. In this window, we look at the evolution of the best bid and ask prices, the depth at the best prices, the spread and the duration between best limit updates. Although the immediate price impact of a trade is a well-studied topic, ${ }^{1}$ the price effects beyond this immediate impact are less well investigated. We examine whether aggressive orders have 'long-run' effects on the best prices in the book. We also look at how the bid-ask spread and depth at the best prices develop before and after an aggressive order. These are probably the most direct measures of market resiliency. In particular, we investigate how fast spread and depth revert to their "pre-aggressive order" level as well as to their average level over time. ${ }^{2}$ Easley, Kiefer and O'Hara (1997) show that between transactions, there is a gradual decrease in information asymmetry. Actually, a more general approach would be to study the depth of the market for different order sizes, but data limitations prevent us from doing so.

We also examine the evolution of transaction prices around aggressive orders by analyzing an event window defined in terms of transactions. We study the short and long-term impact of an aggressive order on transaction prices. The central hypothesis is that all price effects are incorporated in the first transaction price, as predicted by semi-strong form market efficiency (Glosten and Milgrom (1985)).

Our findings can be summarized as follows. When considering the relationship between aggressive orders and the order flow, we find as a first result that, in contrast with BHS95, the least aggressive order types turn out to be the most frequent

\footnotetext{
1 See the pioneering work of Glosten and Harris (1988) and the subsequent literature. Hasbrouck (1995) advocates to use Vector Autoregressions for the long-run price impacts of trading. De Jong, Nijman and Roell (1996) apply the Hasbrouck methodology to Paris Bourse data. Griffiths et al. (2000) investigate the impact of aggressive orders on the Toronto Stock Exchange.

2 Empirically, we capture the "normal" level of the bid-ask spread by its "pre-aggressive order" level. As an alternative, we also use the average level over time.
} 
ones, while the most aggressive types are least frequent. Next to looking at unconditional frequencies, it is interesting as well to consider probabilities conditional upon the current order type. We confirm the diagonal effect as reported in BHS95. This means that an order of a given type is likely to be followed by an order of the same type. Moreover, we show that this effect persists over time in the sense that it not only applies to the next order, but also to subsequent orders. Nevertheless, over time conditional probabilities converge to their unconditional levels.

In our event study for the limit order book, we learn that depth and spread are decreasing in the run-up to an aggressive order. We also find that best bid and ask prices, depth, spread and duration remain significantly higher after an aggressive order when comparing them with their levels just before the aggressive order. For prices we discover long-run impacts of aggressive orders. However, our findings for depth, spread and duration show that these variables return to their original level, before the run-up to the aggressive order started. Depth is restored quickly indicating that liquidity is supplied after is has been consumed. The spread remains higher than it was a few best limit updates before the aggressive order but returns to its level 20 best limit updates before the aggressive order, indicating that this measure of liquidity recovers more slowly. Our results also confirm the findings of BHS95 and Hedvall and Niemeyer (1997) who report empirical evidence for the presence of traders watching the limit order book and providing liquidity when spreads are large. We also discover strategic timing of aggressive orders, i.e. fast order submission when the spread is relatively small. Our results are broadly in line with findings for Xetra reported by Gomber et al. (2004). They focus on one aspect of liquidity, the Exchange Liquidity Measure, ${ }^{3}$ and find that it reverts quickly to its normal level after large transactions - their proxy for a liquidity shock - and that large transactions are timed. Our results on several dimensions of liquidity also indicate that the order book around an aggressive order might be different from an "average" order book. Therefore, and to capture the competitive level as in Cordella and Foucault (1999), we also compare the variables to their sample average. The results reveal that the depth at the best quotes recovers quickly and returns to the sample average within a few best limit updates. The spread significantly increases above average, but also returns to the sample mean, but at a slower pace than depth. Finally, the duration between best limit updates drops below the average after one best limit update order and remains below average for some time.

Transaction prices increase (decline) before the aggressive buy (sell) order. The aggressive order itself leads to a further sharp rise (reduction) in prices, which is however partly reversed in the next transaction. Although subsequent transaction prices exhibit a further tendency to revert to the event transaction price, the longrun effect of aggressive orders on transaction prices remains important.

Summarizing, we conclude from this event study that the market for the stocks we consider is resilient since depth, spread and duration return quickly to their sample average. These variables also gradually return to their level before the run-

\footnotetext{
3 This is the cost of a round-trip trade of given size, computed by the Deutsche Börse.
} 
up to the aggressive order. Only for transaction prices, permanent effects exist. Again, convergence to the new price level is fast. As a final point, we find differences across small and large capitalization stocks, as well as between stocks with small and large tick size. ${ }^{4}$ There are more aggressive orders and stronger price effects for small stocks and stocks with a small tick size.

The remainder of this paper is organized as follows. Section 2 provides an overview of the related literature. Section 3 describes the market structure on the Paris Bourse. The empirical results are presented in three sections. Section 4 describes the data used in our paper. Section 5 deals with the issue of order aggressiveness and order flow. Section 6 analyzes the impact of aggressive orders on resiliency using an event study. Section 7 concludes.

\section{Related Literature}

\subsection{RESILIENCY AND AGGRESSIVE ORDERS}

The topic of resiliency of financial markets did not yet receive much attention in the empirical literature. A recent paper that studies resiliency is Bhattacharya and Spiegel (1998), who investigate NYSE trading suspensions. They define resiliency as the ability to absorb very large shocks. A cross-sectional analysis of all trading suspensions during the period 1974-1988 shows that the various dimensions of liquidity are substitutes: large-cap stocks have lower bid-ask spreads but halt more often. Our paper focuses on resiliency of a limit order market under less extreme circumstances, i.e. after aggressive orders. Coppejans, Domowitz and Madhavan (2003) study the resiliency of the Swedish stock index futures market (OMX). They find that shocks to depth are restored in less than 60 minutes. These results suggest a self-correcting ability for a stock index futures market. However, they are not specific about the source of the shocks.

Our paper adds to the analysis of Coppejans et al. (2003) by focusing on shocks that widen the bid-ask spread caused by large transactions that consume a significant part of the liquidity in the limit order book. BHS95 emphasize the interaction between the order book and order flow for the Paris Bourse. They find that aggressive orders consuming liquidity at the quote are followed by new orders within the bid-ask quotes at the other side of the market. We extend the analysis of BHS95 by not only studying the next order, but also subsequent orders. A recent paper by Gomber et al. (2004) studies Xetra data. They find that liquidity increases prior to large transactions (which they use as their measure for a liquidity shock). This suggests that large transactions are timed as these occur when liquidity is unusually high. Afterwards, liquidity reverts to its normal level but not to its exceptionally high level just before the transaction. These results are in line with our findings. There are however some important methodological differences with our paper. Our

\footnotetext{
4 At this point we want to remark that our sample does not contain very infrequently traded stocks. More details will be given in Section 4.2.
} 
approach includes different dimensions of liquidity while Gomber et al. (2004) focus only on the Exchange Liquidity Measure, which is a measure of transaction costs for one fixed trade size. Secondly, they have observations at a one-minute frequency, which does not enable them to investigate the immediate impact of the large transaction. Moreover, they only make a comparison to the normal level before the transaction, while we also compare with the average over time. Finally, they measure a liquidity shock by considering the 100 largest transactions, while our measure is broader and takes into account the state of the limit order book at the time when the large (aggressive) order is submitted.

There is an extensive literature on order submission in limit order markets. The pioneering work in this area is by Cohen, Maier, Schwartz and Whitcomb (1981). Recent work includes Hollifield, Miller, Sandas and Slive (2003), who study the order submission on the Vancouver Stock Exchange. Hollifield, Miller and Sandas (2004) provide a theoretical model for the tradeoff between supplying liquidity by issuing a limit order and consuming liquidity by issuing a market order, and test the model on data from the Swedish stock exchange. Griffiths, Smith, Turnbull and White (2000) measure price effects of aggressive orders on the Toronto Stock Exchange (TSE) from the perspective of the market participant that submitted the order. The price effect is measured as the realized price of the order ${ }^{5}$ compared to the price immediately prior to the order. They find that only aggressive orders lead to a significantly positive price impact. The price impact of less aggressive orders (e.g. small limit orders or orders that do not generate immediate execution) is small or even negative (conditional on being executed). They find that from the order return perspective, the optimal trading strategy is to buy using limit orders at the bid and to sell using limit orders at the ask. However, this strategy has substantial execution risk.

In our paper we take the perspective of the market as a whole (or all the other participants) and look at a short period of time just before and after the submission of the aggressive order. This enables us to investigate whether the market perceives price effects of aggressive orders as correct or whether the market corrects these effects. Apart from the analysis of the resiliency of the market as a whole, our research differs in two other ways from that from Griffiths et al. (2000). First, we examine the Paris Bourse, where there is no designated market maker as on the TSE. So our research is one of the first to address these issues for a pure limit order market. ${ }^{6}$ Second, our dataset comprises a longer period (six months instead of one). De Winne and D'Hondt (2003) also assess the resiliency of Euronext Paris.

\footnotetext{
5 Griffiths et al. (2000) analyze the impact of orders until full completion.

6 On the TSE the market maker only has a limited role compared to e.g. the NYSE specialist. On the one hand his main role is to provide liquidity and thus may improve resiliency to the market. But on the other hand he mainly provides liquidity to small orders and since the focus here is on aggressive orders (which are usually large), his role would have been limited. So whether this difference in market structures will lead to a difference in resiliency between the Paris Bourse and the TSE remains an empirical question.
} 
They rebuild the full order book for a number of stocks and investigate the depth and spread around an aggressive order, similarly defined as in our approach. When focusing on the total depth (displayed and hidden) at the five best limits, they find that the depth sharply increases after a liquidity shock. However, the relative spread (again taking into account hidden quantities) increases after a liquidity shock and this increase is persistent. From this spread evolution, they conclude that the market is not resilient. In our event study, we do not only consider the displayed depth and spreads but also the prices and durations at the best prices. Moreover, we compare the evolution of all these liquidity characteristics with the pre-aggressive order level as well as with the average over time. We also include an analysis of the determinants of resiliency by pointing at potential determinants of resiliency (stock market capitalization and tick size).

\subsection{TICK SIZE, RESILIENCY AND ORDER FLOW}

A number of theoretical contributions deal with tick size as a determinant of the order flow composition. We are interested in the dynamics after an aggressive order, as these offer insights about the resiliency of a market. We therefore restrict ourselves to theoretical papers considering sequential price formation. ${ }^{7}$ Parlour (1998) shows that systematic patterns in prices and order placement strategies may arise even with only liquidity traders since order placement hinges on past and future expected actions of investors. We find systematic patterns in order flow. In particular, buy orders are more likely to be followed by buy orders while sell orders are more likely followed by sell orders. Moreover, we find persistence in these order flow patterns. Aggressive orders will induce a spread of at least two ticks. Parlour (1998) obtains that in a two-tick market one is more likely to see a drop in the ask after a drop in the bid occurred and vice versa. In line with her theoretical results, we report that aggressive buy and sell orders (leading to multiple-tick spreads) are more likely to be followed by an increase in ask and bid, respectively. Cordella and Foucault (1999) show that when the bidding process is sequential, there are cases where dealers are better off only undercutting by one tick. This is optimal only when the tick size is small. With large tick sizes the wedge between the competitive price and the expected asset value increases. Then a dealer can secure a greater profit by posting the competitive price earlier than a competing dealer. This implies that the time to adjust to the competitive price decreases when the tick size increases. We find that large-tick stocks more often have a one-tick spread than small-tick-size stocks. Our evidence, however, does not reveal that the speed of convergence towards the competitive spread levels, following an aggressive order, depends on the tick size. Foucault et al. (2003) measure resiliency by the probability that the spread will reach the competitive level before the next transaction. They show that tick size has implications for the dynamics of the spread in between transactions. In particular, they show that

\footnotetext{
7 See, for example Seppi (1997) for the effects of tick size in a static setting.
} 
when the tick size is small, traders may find it optimal to undercut or outbid the best prices by more than one tick in order to speed up execution. This depends on the proportion of patient traders in the population. Ultimately, it is an empirical question how a market's resiliency functions and to what extent its liquidity is reestablished after an aggressive order. It is precisely this question that we address in this paper.

A number of empirical papers have investigated the impact of tick size changes on market quality. Bacidore (1997), Ahn et al. (1998) and Griffiths et al. (1998) consider the April 1996 reduction in tick size on the TSE, while Goldstein and Kavajecz (2000) deal with the changes in tick size and the liquidity provision on the NYSE. Chordia et al. (2001) study the effect of the reduction in tick size on the NYSE. They show that after the reduction in tick size, the inside spread significantly decreased, but depth at the best bid and ask also decreased. Bourghelle and Declerck (2004) investigate the market quality of the Paris Bourse following the introduction of the Euro. Interestingly, they find that only the depth at the best prices is significantly affected whereas the spreads remain unaltered. Stocks obtaining a decrease (increase) in tick size experience a decrease (increase) in the depth at the best prices.

\subsection{FIRM SIZE, RESILIENCY AND ORDER FLOW}

Theory also suggests that heterogeneity with respect to firm size is important for resiliency and the composition of the order flow. Empirically, there is a negative relation between firm size and the bid-ask spread (see McInish and Wood (1992), and the review in Madhavan (2000)). Cordella and Foucault (1999) argue that for a given tick size, the speed of adjustment to the competitive quotes must be faster for large firms. Thus large firms should show more resilient markets than small firms. Foucault (1999) shows that when asset volatility increases the proportion of limit orders should increase. The proportion of limit orders for small-capitalization stocks must be larger than the one for large-capitalization stocks, since volatility is negatively related to equity capitalization (see Hasbrouck (1991)).

\section{Market Structure of the Paris Bourse}

The Paris Bourse is a computerized limit order market that uses a centralized electronic system, known as CAC (Cotation Assistée en Continu). ${ }^{8}$ Similar systems are used in Brussels (NTS), Stockholm (SAX) and Toronto (CATS). The exchange opens at 10:00 a.m. with a batch auction after which a continuous auction takes place until 5:00 p.m. Note that nowadays the exchange opens at 9:00 a.m. and runs until 5:30 p.m., but the times mentioned here were valid during our sample period (March-August 1998). There are no market makers or floor traders. Liquidity is

\footnotetext{
8 The Paris Bourse merged in 2000 with the Amsterdam Stock Exchange and the Brussels Stock Exchange into Euronext.
} 
provided by the public limit order book only. A trader can choose between different types of orders. He can submit a limit order, which specifies the quantity to be bought or sold, the price and the date when the order will be withdrawn (unless the order is 'good till cancelled'). A trader can also choose to submit a market order, which only specifies the quantity and direction of the trade and is executed immediately at the best possible price (provided the limit order book is not empty). If the total quantity of the available orders in the limit order book at the best price does not suffice to fill the whole market order, the remaining part of the market order is transformed into a limit order at the transaction price. Hence, market orders do not automatically walk up the limit order book, and do not always provide immediate execution of the whole order. The way of achieving full execution of an order is to use an aggressive limit order, meaning an order that has a higher price than the best prices at the other side of the market and walks up the limit order book. For a buy (sell) order, this means it has a price higher (lower) than the best ask (bid). An aggressive limit order therefore provides a faster execution of a large transaction than a market order. Finally, traders can also submit hidden orders, which are limit orders that are not fully visible to other traders. For more details on hidden orders, we refer to BHS95 or D'Hondt et al. (2002).

The price of a limit order can be any price on the pricing grid determined by the tick size. The tick size of a stock depends upon its price level. Stocks with a price below $5 \mathrm{FF}$ have a tick size of $0.01 \mathrm{FF}$, if the price is between 5 and $100 \mathrm{FF}$ this is $0.05 \mathrm{FF}$, between 100 and $500 \mathrm{FF}$ it is $0.1 \mathrm{FF}$ and stocks with prices between 500 and 5000 FF have a tick size of 1 FF. For prices above 5000 FF the tick size is $10 \mathrm{FF}^{9}$ This translates into a relative tick size of minimum $0.2 \%$ for stocks with the smallest price. Stocks in subsequent price categories have a relative tick size between $1 \%$ and $0.05 \%, 0.1 \%$ and $0.02 \%$, and 0.2 and $0.02 \%$ respectively. For stocks with prices above $5000 \mathrm{FF}$, the relative tick size is maximum $0.2 \%$. This is fairly small compared to other exchanges. Until 1997, NYSE used a tick size of $1 / 8 \$$ for stocks above one dollar and $1 / 16 \$$ for stocks between $0.5 \$$ and $1 \$$, which results in a maximum relative tick size of $12.5 \%$. From 24 June 1997 onwards, the minimum price variation for stocks above one dollar was reduced to $1 / 16 \$$, resulting in a halving of the maximum relative tick size to $6.25 \%$, which is still considerably larger than on the Paris Bourse. See also e.g. Angel (1997) for a comparison of tick sizes across countries.

Shares are traded on a monthly settlement basis. The Société des Bourses Françaises (SBF) acts as a clearing house. The member firms of the Bourse submit orders directly into the CAC system via a local terminal. Transactions occur when the price of a trader hits the best price on the opposite side of the market. Limit orders are stored and executed according to first price priority and then time pri-

\footnotetext{
9 The tick sizes mentioned are these that were in use during our sample period. After the introduction of the Euro, the tick sizes changed, see Bourghelle and Declerck (2004) for a more detailed discussion.
} 
ority. ${ }^{10}$ All market participants can contribute to liquidity by putting limit orders on display. There is some scope for negotiated deals if the limit order book is insufficiently deep. A financial intermediary can negotiate a deal directly with a client at a price within the bid and ask price (also know as the fourchette), provided that the deal is immediately reported to the CAC system as a cross order. For trades at prices outside the fourchette, the member firm acting as a principal is obliged to fill all limit orders displaying a better price than the negotiated price within five minutes.

\section{Data Description}

\subsection{DATA SET}

The sample used in this paper consists of 20 stocks listed on the Paris Bourse. To ensure that our sample is representative for the Paris Bourse, the stocks were chosen on basis of 2 criteria. First, we distinguish stocks with a small and large market capitalization, where the latter are defined as stocks that are included in the CAC40 index, while the former are not. Secondly, as mentioned above, listed stocks differ in their tick size, which in our sample can be 0.1 FF or 1 FF. From the stocks falling in each of these four categories, we randomly selected five. We refer to Table 1 and section 4.2 for more details. The sample period ranges from 23 February 1998 until 24 August 1998, which are 123 trading days. We assured that during this sample period the absolute tick size of a given stock is constant, because a varying tick size, i.e. a tick size that changes from $0.1 \mathrm{FF}$ to $1 \mathrm{FF}$ or the other way around, might bias our results.

The data are taken from the SBF database of the Paris Bourse. Since 1990, the Paris Bourse has set up a database, available on CD-ROM, with detailed information on all kind of securities. For the selected stocks, we use the order file, which contains data on all incoming orders; the transaction file, containing all transactions; and the best limit file, which keeps track of all best bid and ask prices, as well as the depth at these prices. Our dataset is therefore similar to the one used in Bisière and Kamionka (2000). We eliminated all pre-opening orders from our data set because the trading mechanism during this period, which is a batch auction, differs from the continuous auction setting during the day. For a detailed discussion of the pre-opening period and the opening procedure of the Paris Bourse, see Biais et al. (1999).

A limitation of the SBF data set is that it does not provide information about order modifications and cancellations. In other words the data set does not allow to follow orders until completion, as they may be withdrawn or be repriced before (full) execution. However, not observing order modifications and cancellations does not hamper our order classification methodology (see Section 5), as we take the state of the order book just before the arriving order into account.

\footnotetext{
10 Hidden orders loose time priority for the part that is not publicly displayed.
} 


\subsection{DESCRIPTIVE STATISTICS}

In Table I, the characteristics of the different stocks, their composition and some descriptive statistics of the data are presented. In this table, we grouped the stocks by category. First, the minimum, maximum and average best ask prices are given. Notice that for small-tick stocks, these are located between 100 and $500 \mathrm{FF}$, while for stocks with a large tick size these are above 500 FF. This ensures the same tick size over the sample period. Also, the average depth at the best prices is shown. For a majority of the stocks the depth at the best bid is smaller than the depth at the best ask. Also, in general, the depth in number of shares is smaller for small stocks than the depth for large stocks. Next, the average daily ask returns and their standard deviations are calculated. For a majority of the stocks, the average daily return is negative. The standard deviation is smaller for stocks with the large tick size. Subsequently, the average and median bid-ask spread, expressed in FF, are shown, as well as the proportion of the time the spread was $0,1,2, \ldots$ ticks. ${ }^{11} \mathrm{~A}$ remarkable result is that for stocks with a small tick size $(0.1 \mathrm{FF})$, the proportion of spreads larger than 5 ticks is more than $50 \%$, while for large-tick stocks there is a large proportion of 1 or 2 tick spreads. This might be an indication that for stocks with a tick size of $1 \mathrm{FF}$, this minimum price variation is often a binding constraint, while this is not the case for the small tick size. This result is also in line with Cordella and Foucault (1999), who argue that the speed of convergence towards the competitive spread level is higher for large-tick stocks. This implies that one-tick spreads are more likely for large-tick stocks. The average relative spread (the ratio of average spread and average midprice) is larger for small stocks. Given the size of the stock, the differences between tick sizes are on average small. The last rows of Table I provide details on the market capitalization of the stocks and the average daily traded volume (in million FF), as well as their position in the ranking of French stocks. It shows that the stocks in our sample are distributed across different quintiles on the Paris Bourse, meaning that we are indeed analyzing different groups of stocks. Most of the stocks (18 out of 20) are from the top 100 in terms of market capitalization. Since the top 100 traded stocks comprise $93 \%$ of the global volume of transactions in French stocks, we are using a sample which covers stocks that are most often traded on the Paris Bourse. We do not consider very infrequently traded stocks in our sample.

\section{Order Aggressiveness and Order Flow}

\subsection{ORDER CLASSIFICATION METHODOLOGY AND FREQUENCY OF ORDER TYPES}

In order to characterize the order submission behavior, all incoming orders are classified according to the scheme proposed by BHS95 and also used in other papers, see e.g. Bisière and Kamionka (2000). A distinction between orders is made

\footnotetext{
11 A possible situation with a zero spread is a fill-or-kill order.
} 


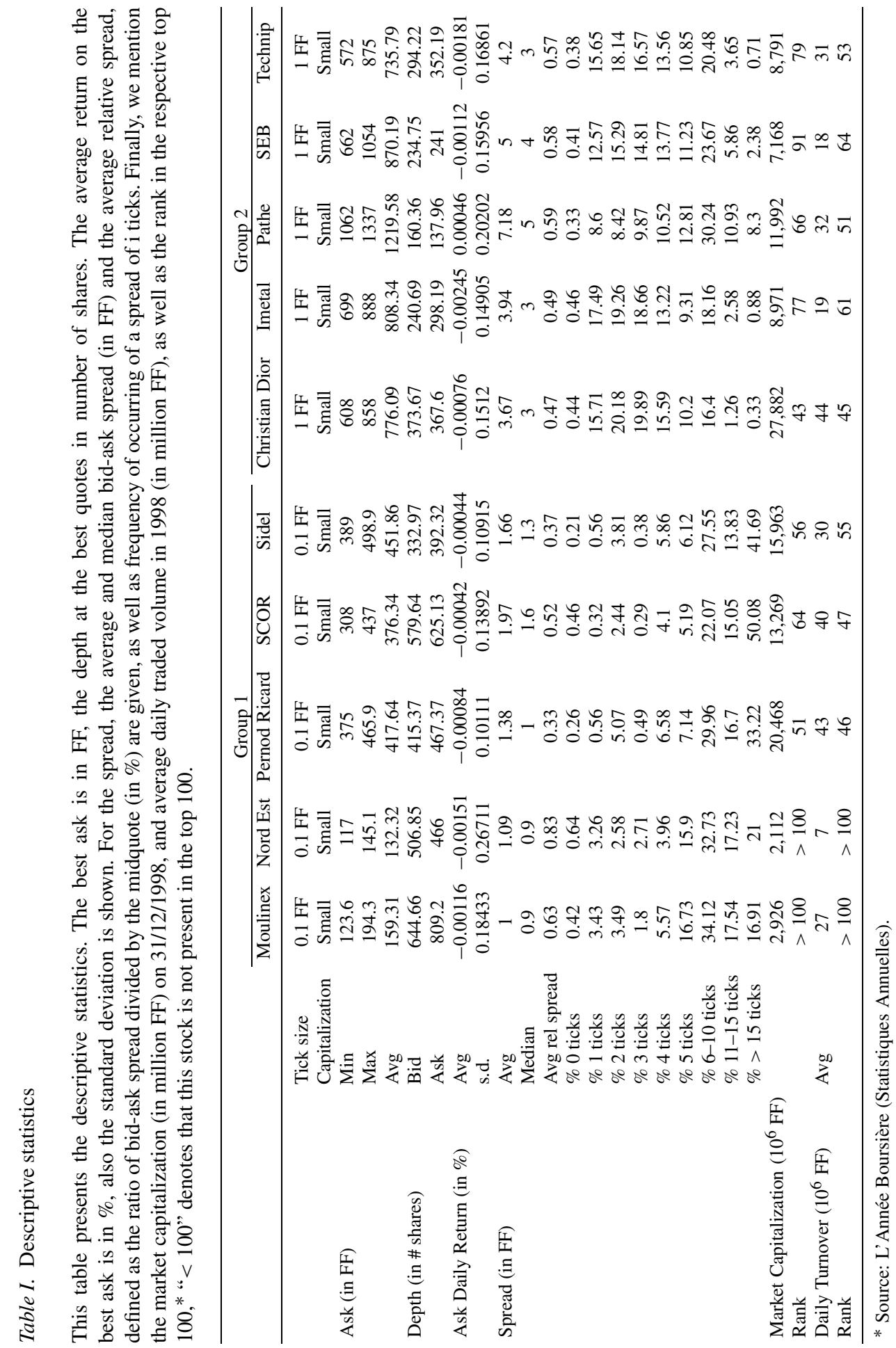




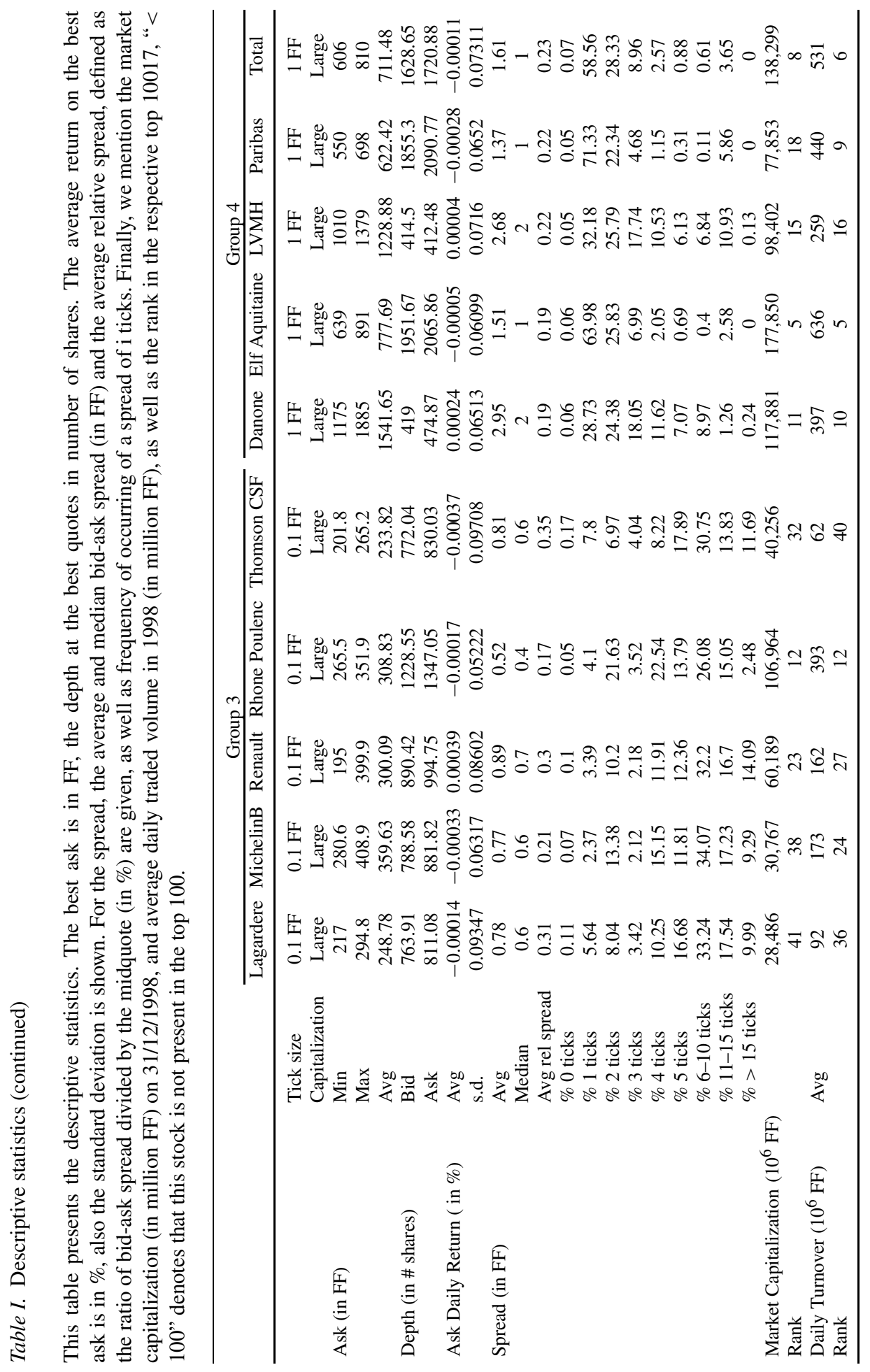


on the basis of the direction of the order (buy or sell), and of its aggressiveness. The classification of buy orders is depicted by Figure 1. Buy orders are classified into aggressiveness order types 1 to 6 , where 1 is the most aggressive buy order type, and 6 is the least aggressive. An order of type 1 is an order to buy a larger quantity than is available at the best ask at a price that is higher than the best ask. This means that these orders walk up the limit order book and result in multiple trades. An order of type 2 is an order for a larger quantity than available at the best ask, but that does not walk up the limit order book above the best ask. The reason for this can be twofold. First, the order can be a limit order with a price equal to the best ask, but with a larger quantity than the depth at the best ask. Secondly, the order can be a market order which has an order size larger than the one available at the best price. In the latter case, the rules of the Paris Bourse forbid such market order to walk up the limit order book. For both, the part of the order that is not executed immediately is converted into a limit buy order. Orders of type 3 are orders to buy a quantity that is lower than the one offered at the best ask, hence they result in full and immediate execution. In contrast, the remaining buy order types are not executed immediately, so they do not result instantaneously in a transaction. Type 4 orders have a price worse than the best ask, but better than the best bid price, while type 5 orders have a price exactly at the best bid. The remaining orders are collected in type 6 . Sell orders are classified in a symmetric way, resulting in order types 7 , the most aggressive sell order, to 12 , which is the least aggressive sell order type.

On both sides of the market, the most aggressive order types immediately result in transactions and cause a price movement. Less aggressive order types, such as 3 and 9, still result in transactions, but do not give rise to an update of the best prices. They only reduce the depth at the best ask and bid respectively. The sum of these three types of orders is a proxy for "market orders" as in Foucault (1999). Order types 4 and 5, and 10 and 11 do not give rise to transactions while the prices of the least aggressive orders 6 and 12 are even worse than the current best prices in the market. Since the focus of this paper is on aggressive orders, our attention will mainly go to the two order types on each side of the market that are most aggressive, being types 1 and 2 for buy orders and 7 and 8 for sell orders.

The frequency of order types is documented in Table II. This frequency table shows that the least aggressive order types (6 and 12) have the highest frequency of occurring, followed by types 3 and 9 . On the other hand, the most aggressive order types ( 1 and 7 ) have the lowest probability of occurring. Somewhat less aggressive orders (types 2 and 8 ) however have already a much higher frequency. The results are similar for buy and sell orders.

BHS95 also report that the most aggressive order types are the least frequent, but some of their other results are different from ours. In BHS95, type 3 and 9 orders are most frequent, while type 2 and 8 are much more infrequent than in our results. Griffiths et al. (2000) report frequencies for the TSE. They also find that types 3 and 9 are most frequent and types 1 and 7 most infrequent. However, in 


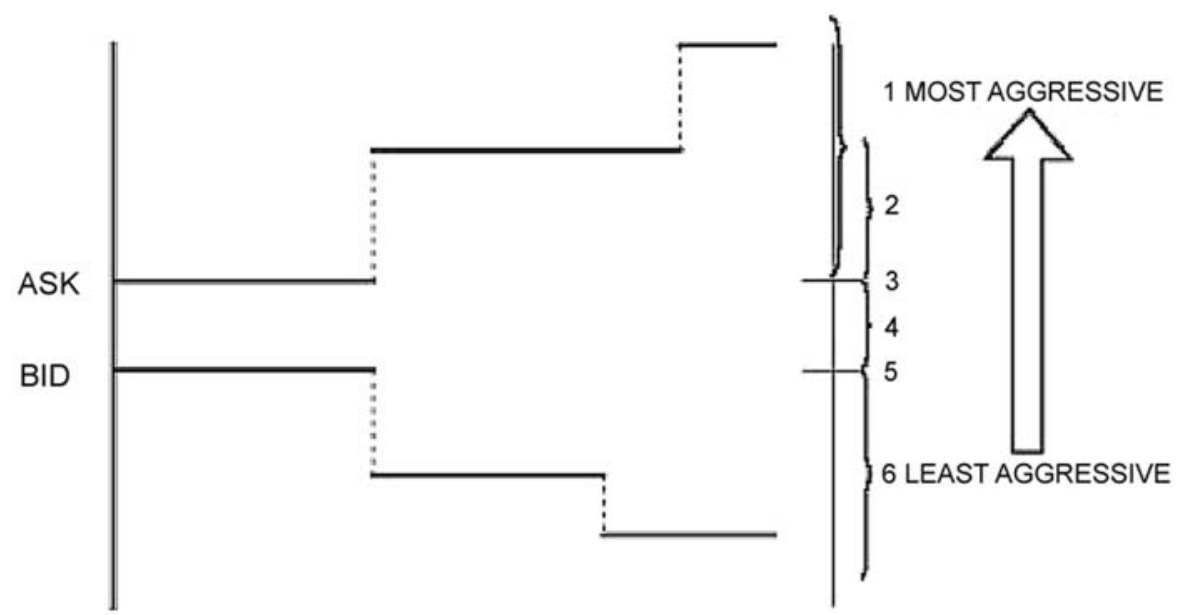

Figure 1. Classification of buy orders (BHS95). This figure depicts the order classification scheme for buy orders (sell orders are classified in a symmetric way). An order of type 1 is an order to buy a larger quantity than is available at the best ask at a price that is better than the best ask. An order of type 2 is an order for a larger quantity than available at the best ask, but that is not allowed to walk up the limit order book above the best ask. The part of these orders that is not executed immediately, is converted into a limit order. Orders of type 3 are orders to buy a quantity that is lower than the one offered at the best ask. The remaining buy order types are not executed immediately, so they do not result instantaneously in a transaction. Type 4 orders have a price worse than the best ask, but better than the best bid price, while type 5 orders have a price exactly at the best bid. The remaining orders are collected in type 6 .

contrast with BHS95, and in accordance with our results, type 2 and 8 orders are much more frequent than 1 and 7. On TSE, types 1 and 7 are even more infrequent than on the Paris Bourse. One possible explanation is that some TSE stocks have bid-ask spreads equal to the tick size. This drives traders to trade at the best prices because they cannot improve the prices. This may explain why a larger fraction of type 3 orders (small market orders) and a smaller fraction of type 4 orders are observed.

The results presented in Table II apply to all groups of stocks, but nonetheless there are also some notable differences between groups. Although infrequent in all groups, types 1 and 7 are most infrequent in groups with a large tick size (groups 2 and 4). On the other hand type 2 and 8 are more frequent in the large tick size groups than in groups with a small tick size.

\subsection{CONDITIONAL PROBABILITY OF ORDER TYPES}

The results in Table II are unconditional probabilities. In order to analyze the influence of aggressive orders on the subsequent order flow, we turn in this section to conditional probabilities. Table III presents the probabilities that the next order is of a certain type, conditional upon the aggressiveness type of the current order. 
Table II. Frequency of order types

This table presents the unconditional frequency of occurring, expressed in \%, of the different order types for the various groups of stocks. The averages across group members are shown. The last row gives the total number of orders for the specific group. The definition of the order types can be found in Figure 1.

\begin{tabular}{lcccc}
\hline & $\begin{array}{c}\text { Group 1 } \\
\text { Small stocks, } \\
\text { tick size 0.1 FF }\end{array}$ & $\begin{array}{c}\text { Group 2 } \\
\text { Small stocks, } \\
\text { tick size 1 FF }\end{array}$ & $\begin{array}{c}\text { Group 3 } \\
\text { Large stocks, } \\
\text { tick size 0.1 FF }\end{array}$ & $\begin{array}{c}\text { Group 4 } \\
\text { Large stocks, } \\
\text { tick size 1 FF }\end{array}$ \\
\hline Type 1 & 3.89 & 2.82 & 3.46 & 1.91 \\
Type 2 & 5.70 & 5.76 & 5.63 & 6.11 \\
Type 3 & 10.27 & 10.40 & 10.41 & 11.29 \\
Type 4 & 8.54 & 7.16 & 8.69 & 4.22 \\
Type 5 & 5.91 & 7.17 & 6.36 & 8.39 \\
Type 6 & 17.33 & 16.11 & 16.08 & 14.79 \\
Type 7 & 3.75 & 3.03 & 3.42 & 1.86 \\
Type 8 & 5.40 & 6.53 & 5.97 & 7.39 \\
Type 9 & 7.80 & 8.84 & 10.49 & 14.68 \\
Type 10 & 7.04 & 6.73 & 7.72 & 4.10 \\
Type 11 & 6.38 & 7.37 & 5.97 & 8.16 \\
Type 12 & 17.98 & 18.09 & 15.79 & 17.10 \\
Total Number of Orders & 294775 & 199073 & 1048215 & 1141954 \\
\hline
\end{tabular}

To conserve space, and as the results do not differ dramatically across groups of stocks, we present unweighted averages in Table III. In the table, each element can be interpreted as the probability that a current order of the type given by the row is followed by an order of the type given by the column. The last row presents the unconditional probabilities of the type given by the column. The last two columns show the probabilities that an order of the type given by the row is followed by respectively a buy order or sell order.

The probability that an order of a certain type is followed by an order of the same type is relatively high, confirming the diagonal effect also found in other studies (e.g. BHS95). This is indicated by the fact that the elements on the diagonal of the table are in almost all cases the highest in the column. The diagonal effect may result from strategic order splitting strategies, imitating behavior, or similar reactions to events by market participants. The last two columns in each panel show that buy orders are more likely to be followed by buy orders, while sell orders are more likely followed by sell orders. This is in line with Parlour (1998) who showed that systematic patterns in order placement strategies might arrive. Finally, in all panels, there is high probability that an order of type 1 is followed by an order of type 4. i.e. an aggressive order is often followed by a price improving limit order 


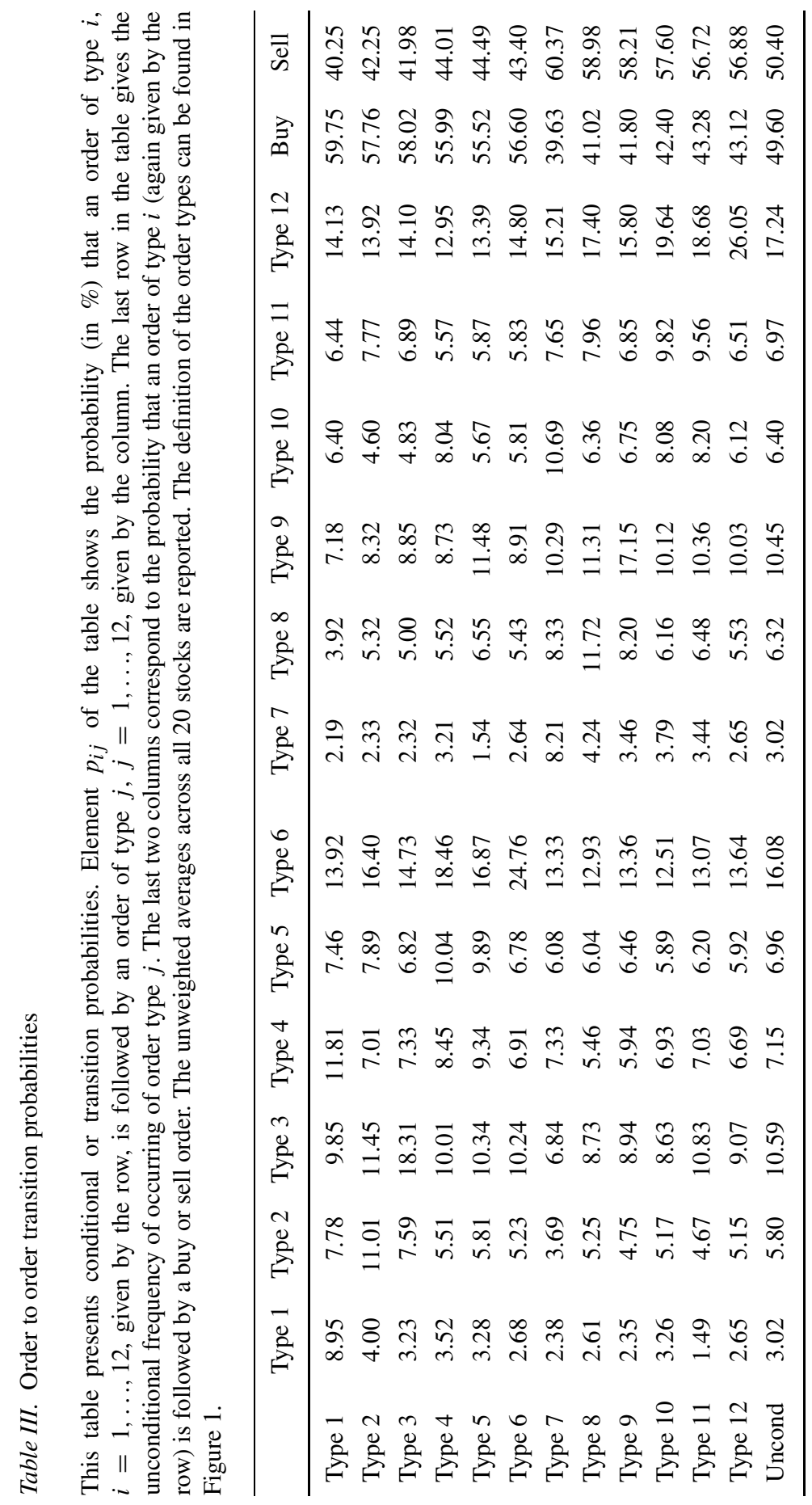


on the same side of the market. This result is in correspondence with BHS95. An explanation for this pattern might be that it is the result of traders that are splitting orders. A similar result holds for sell orders: the probability that an order of type 7 is followed by an order of type 10 is relatively high. The result that aggressive buy and sell orders (leading to multiple-tick spreads) are more likely to be followed by an increase in ask and bid, respectively, is reminiscent of the two-tick model in Parlour (1998). The bid-ask spread widens after an aggressive buy or sell order (type 1 or 7). Since limit order traders can earn this spread, there is an increased incentive to provide new liquidity within the best bid-ask prices.

In Table III, we looked at the first order following an aggressive order. An interesting extension is to study also subsequent orders. In Figure 2, the evolution of the diagonal effect over time is drawn. More specifically, the probability is given that an order of type $i, i=1, \ldots, 12$, at time $t$ is followed by an order of the same type $i$ at time $t+k, k=1, \ldots, 75$. We find that the diagonal effect persists beyond one order. But the conditional probabilities do converge to the unconditional levels. Remarkable is also the difference between orders of type 4 and 10 and other types. The probability that an order of these types is followed by an order of the same type is relatively small, compared with the other order types. Often further undercutting becomes impossible and the provided liquidity needs to be consumed first before similar order types become possible. The next order that again provides liquidity within the best prices will only be some orders later. For this reason, convergence for these types is not as pronounced as for the other types.

The (not reported) differences between groups show that the convergence to the unconditional levels is smoother for large stocks than for small stocks and occurs slightly faster for the smaller stocks for the more aggressive order types. There are no important differences between groups having different tick sizes.

\section{Market Impact of Aggressive Orders}

\subsection{METHODOLOGY}

To study resiliency and investigate the market impact of aggressive orders, we take an event study type of approach. More specifically, we look directly at what happens in the limit order book in a small period of time around an aggressive order. The advantage of this methodology is that we describe what in reality is going on in the limit order book. We start from an aggressive order of type $i$, with $i=1,2,7$ or 8 (respectively the two most aggressive buy and sell order types). Around the submission of such order, we create a window of 10 best limit updates (for short blim updates) before and 20 blim updates after the order. Blim updates are defined as an update of either the best bid or ask price, or the depth at these best prices (or a combination of both). Time $t=0$ captures the state of the limit order book just before the aggressive order. Within each window, we analyze the evolution of best bid and ask prices, the depth at these prices, the bid-ask spread and the duration between blim updates. More specifically, for each stock, we take their 


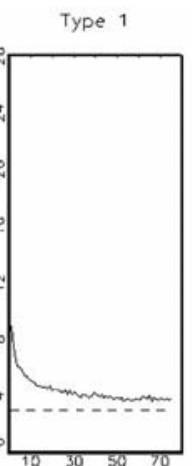

Type 7
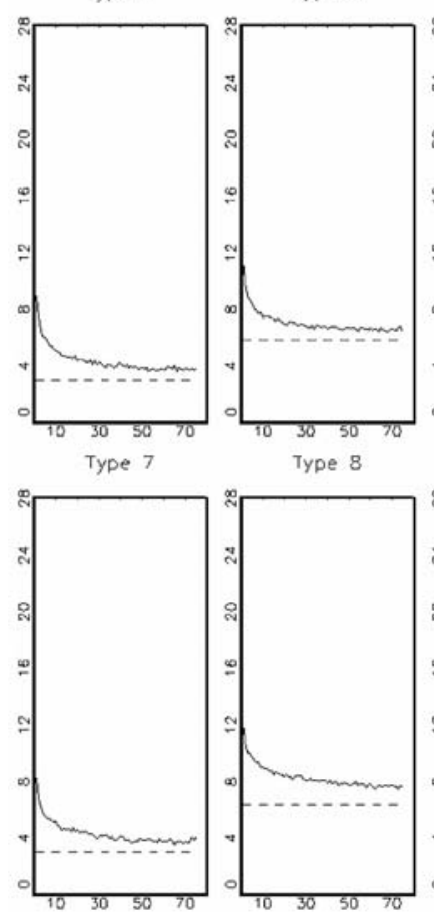

Type 3

Type 4

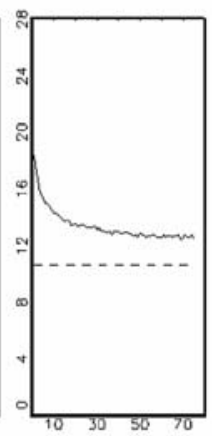

Type 9
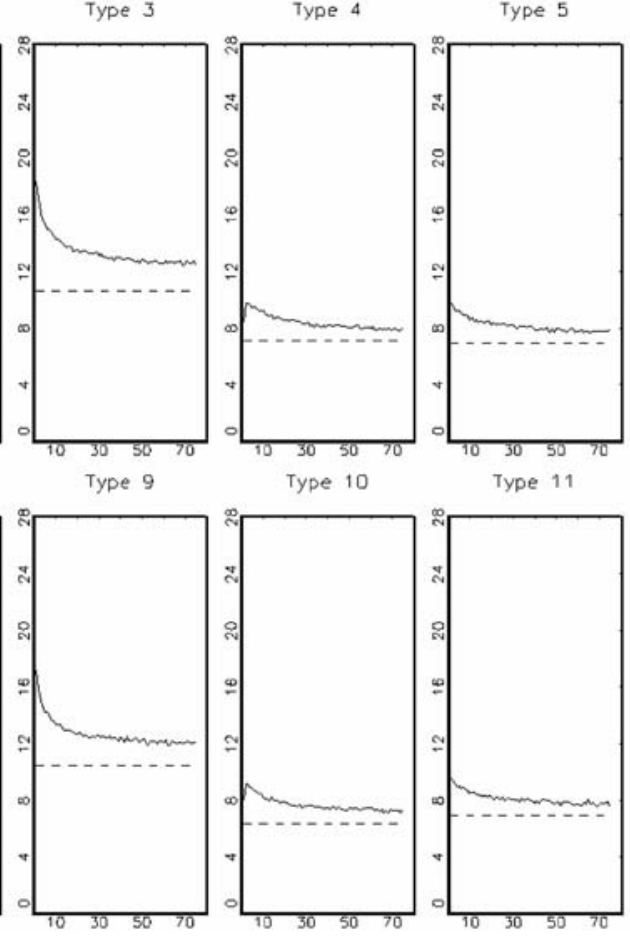

Type 11

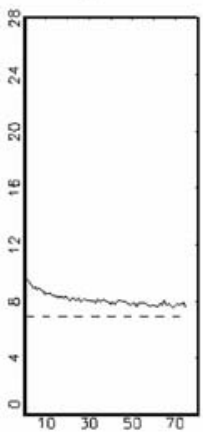

Type 6

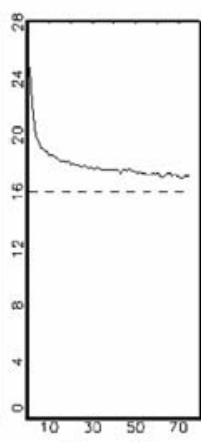

Type 12

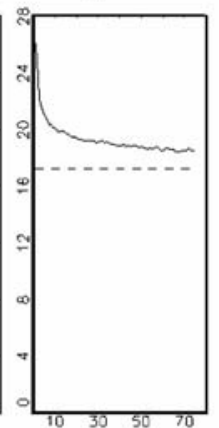

Figure 2. The diagonal effect over time. The full lines in this figure represent the probability that an order of type $i, i=1, \ldots, 12$, at time $t$ is followed by an order of the same type $i$ at time $t+k, k=1, \ldots, 75$. The dashed lines present the unconditional frequency of the order types $i$. The averages across stocks are plotted in the figure. The definition of the order types can be found in Figure 1.

average values $t=-10, \ldots, 20$ around an aggressive order. Then, the unweighted averages across the 20 stocks are calculated. Notice that by looking at what happens before and after the submission of aggressive orders, we generalize the BHS95 analysis to order submission behavior. They find shifts in both bid and ask quotes after large transactions.

\subsection{RESULTS}

The results of our event study are presented graphically in Figure 3 and analyzed numerically in Table IV and Table V. Panels A, B, C, and D in Figure 3 and Tables IV and $\mathrm{V}$ present the results for a type 1 order, a type 2 order, a type 7 order and a type 8 order submitted at time zero, respectively.

Figure 3 plots the evolution of best ask and bid prices in the limit order book, depth at the best ask and bid, spread and duration in a window around an aggressive order. Important in the interpretation is that the values of the variables are calculated relative to the value at the time of the submission of the order of type $i$, which 
Best bid and ask around order of type 1

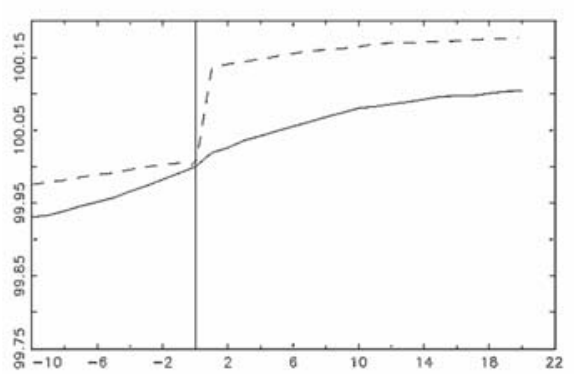

Spread around order of type 1

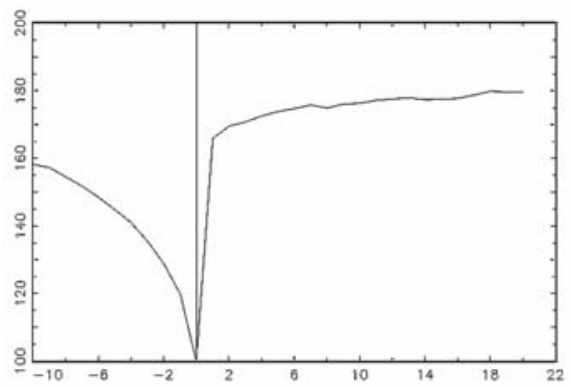

Depth ot best prices around order of type 1

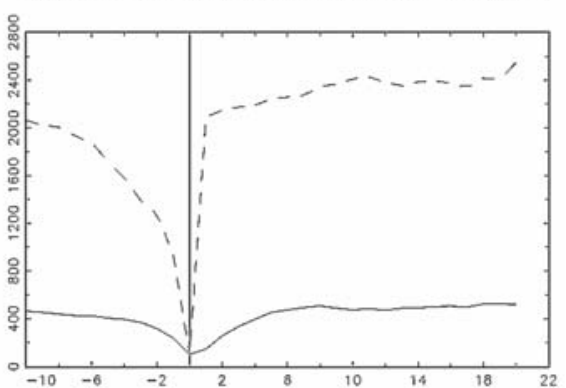

Duration around order of type 1

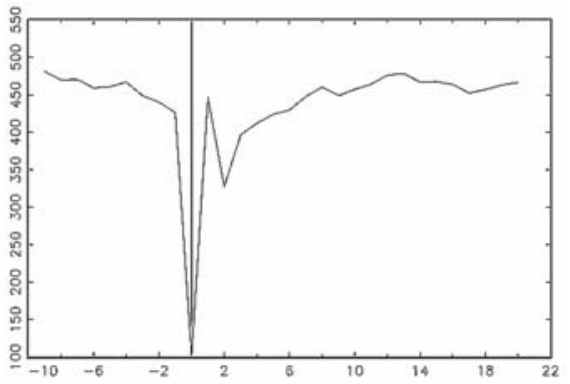

Figure 3. The limit order book around aggressive orders. This figure presents the order book around aggressive orders of type 1,2, 7 and 8 (the definition of the order types can be found in Figure 1). Time $t=0$ corresponds to the limit order book just before the aggressive order. Time $t=1$ is the limit order book following the aggressive order. In Panel A we assume that an order of type 1 is submitted. Around the submission, we consider a window of 10 best limit updates (prices or depth or both) before and 20 updates after the submission. The graphs in Panel A plot the evolution of the best bid and ask (full and dashed lines respectively), the depth at the best bid (full line) and ask (dashed line), the bid-ask spread and the duration between best limit updates within this window. For each variable, the values are relative to their value at the time of submission of the order of type 1, which is set to 100. In other words, they show how each variable changes, compared to the time of the aggressive order. For each variable, the unweighted averages across all stocks are drawn. Panels B, C and D have the same interpretation, but assume respectively an order of type 2,7 and 8 at time zero.

was set equal to 100. This implies that the lines express how the variable changed compared to time zero, the time just before the aggressive order. Moreover, the results are presented in order time. To have an idea about the effect in calendar time, one can use the average duration between best limit updates. This average duration is 84 seconds for group 1, 100 seconds for group 2, 45 seconds for group 3 and 34 seconds for group 4 . From this, it can be derived that a 20 period interval after the aggressive order will on average comprise a period ranging between about 33 minutes for stocks of group 2 and 11 minutes for group 4. A second point concerning the interpretation of our results is related to the timing assumption. The time index refers to the values of prices and depth at the time the order was 


\section{Panel B: Type 2 order}

Best bid and ask oround order of type 2

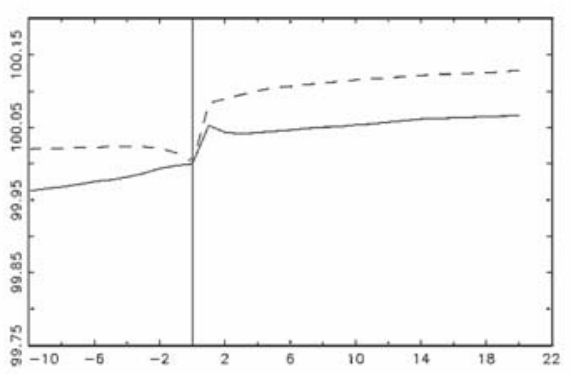

Spread around order of type 2

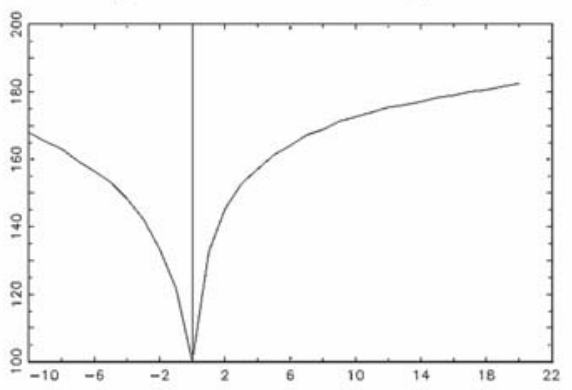

\section{Panel C: Type 7 order}

Best bid and ask oround order of type 7

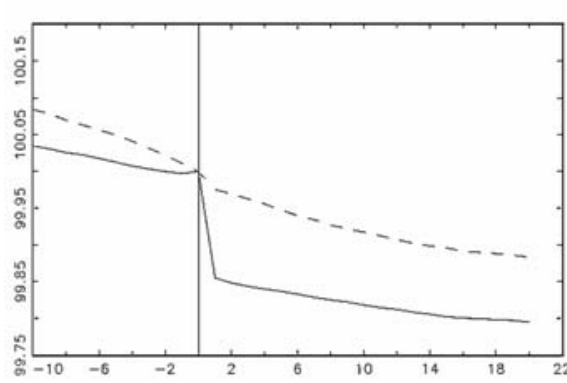

Spread oround order of type 7

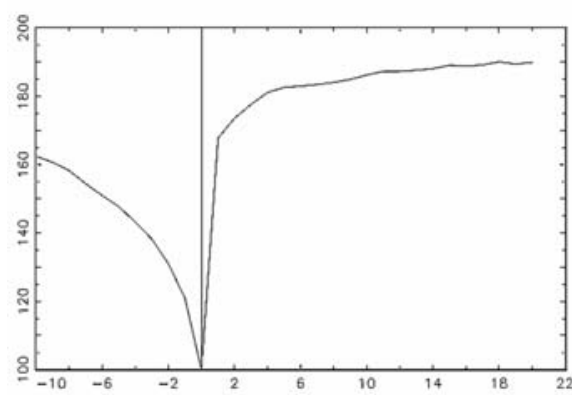

Depth at best prices around order of type 2

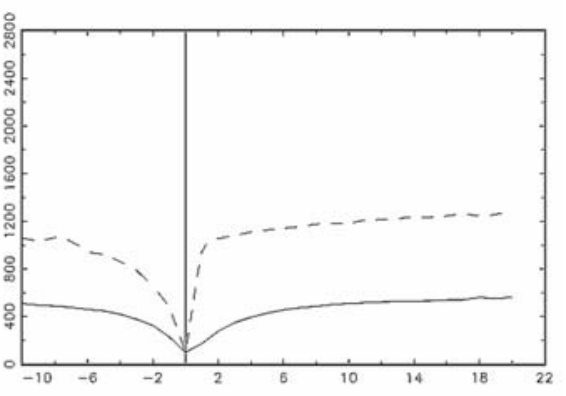

Duration around order of type 2

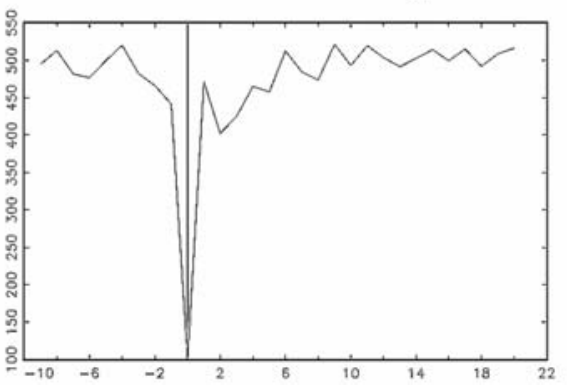

Depth ot best prices around order of type 7

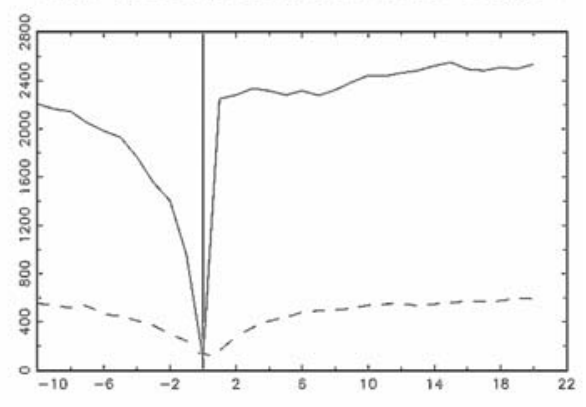

Duration around order of type 7

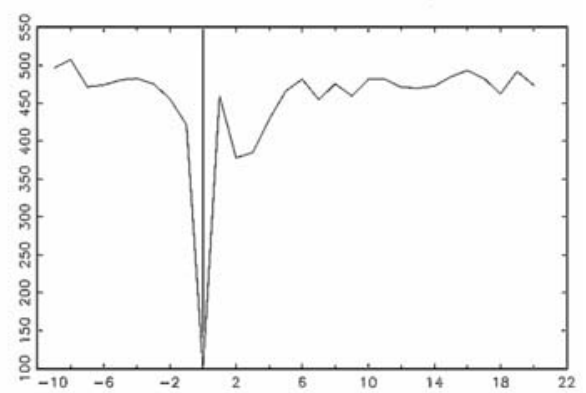

Figure 3. Continued. 

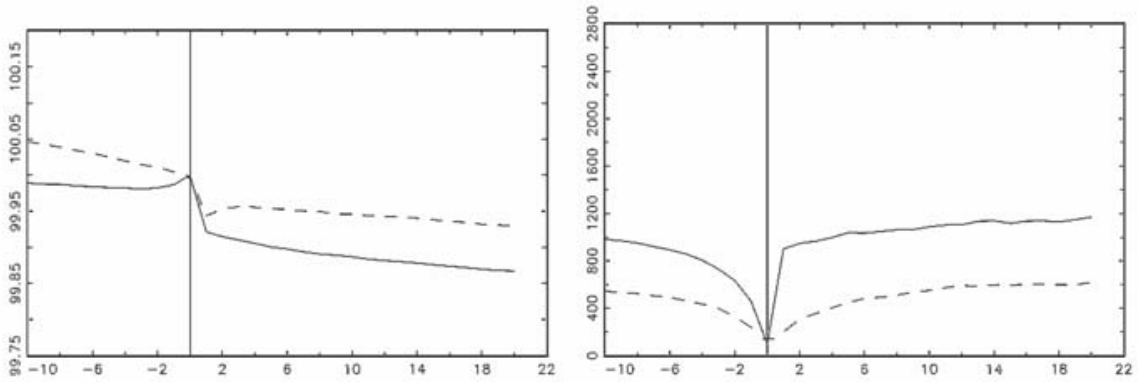

Spread around order of type 8

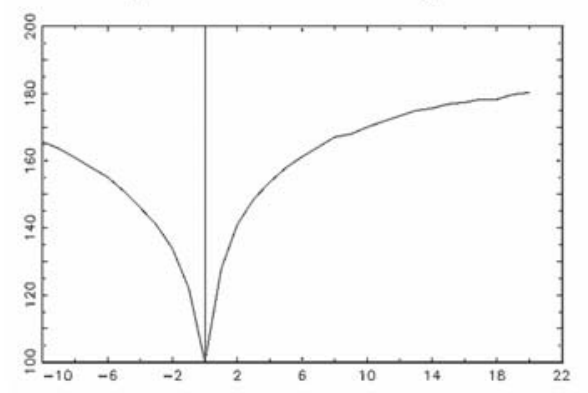

Duration around order of type 8

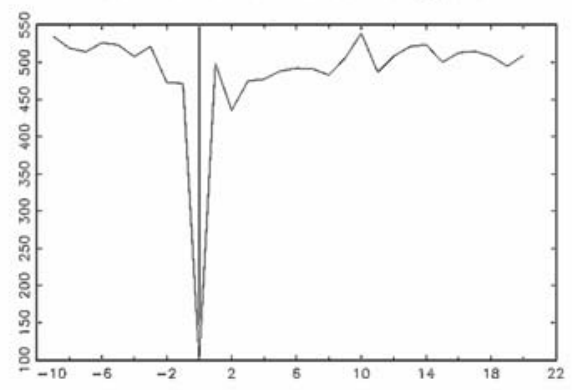

Figure 3. Continued.

submitted. This means that if the order submitted at time zero causes a blim update, the effect in the figure is visible only in period one.

Table IV provides a numerical analysis of (the evolution of) the variables depicted in Figure 3, and shows the results of tests of whether best bid and ask prices, depth, spread and duration around an aggressive order are significant different from their values at time 0 , the time of submission of the aggressive order. This was done by means of a $t$-test. In each column, the first (second) element between brackets gives the number of stocks, out of 20 , for which this difference was significantly positive (negative) at the $5 \%$ level. Between square brackets, we also report the $p$-value of a binomial test, based on the number of positive and negative signs (out of 20).

In Table V, we normalized depth, spread and duration by the sample average of the specific variable. ${ }^{12}$ The reason to present this alternative is that the limit order book in the event window might not be an "average"/representative order book. For example, as we will discuss later in this section, the depth and the spread just before an aggressive order are relatively small. Moreover, this sample average may be a proxy for the competitive level as in Cordella and Foucault (1999). There-

\footnotetext{
12 We only present results for normalized depths, spreads and durations, and not for ask and bid prices. The best ask and bid prices are non-stationary time series and hence a comparison with their average over time is not meaningful.
} 


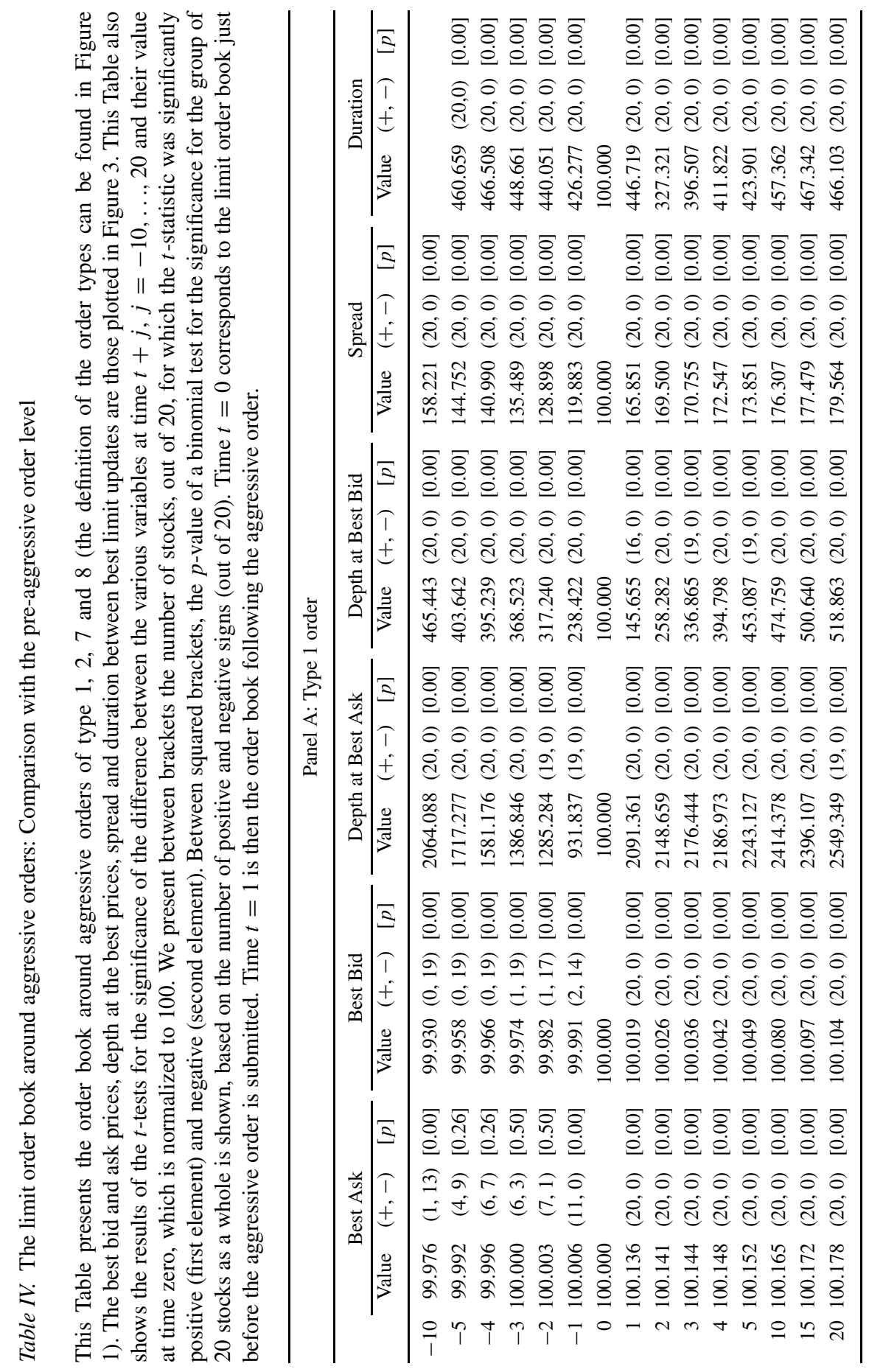




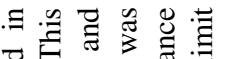

可的导氖:

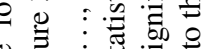

8.5000

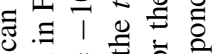

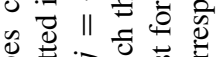

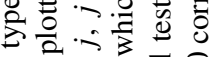

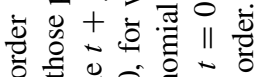

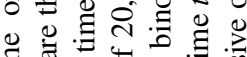

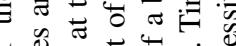

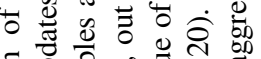

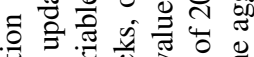

$\Rightarrow$ 훙

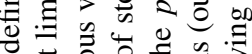

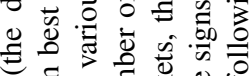

$\infty$ ब๊

急 $\overline{0}$

人 5 势

i 可 0

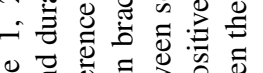

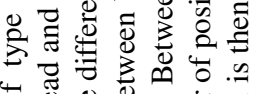

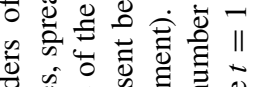

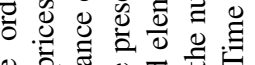

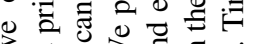

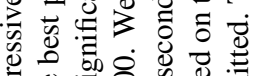

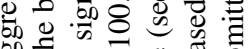

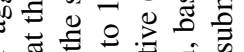

등

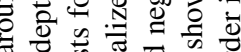

की

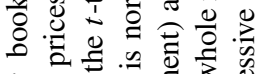

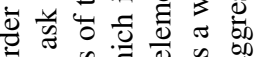

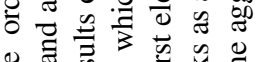

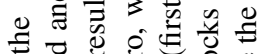

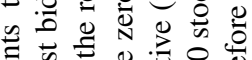

चु

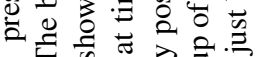

은

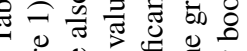

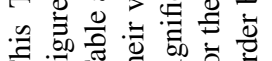

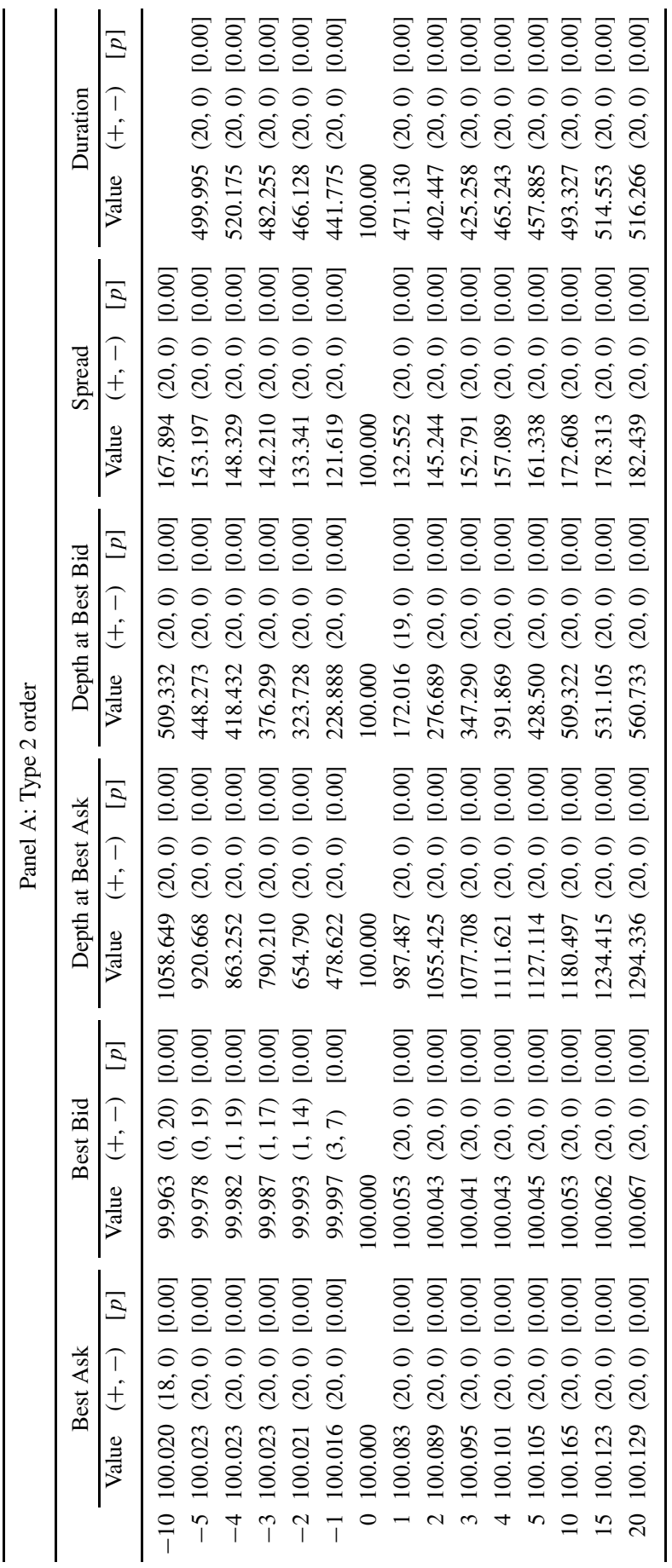




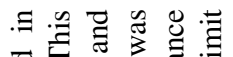

的穴氖

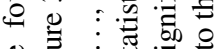

8000

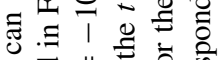

४

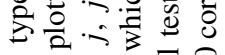

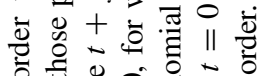

๑

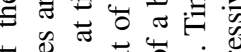

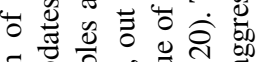

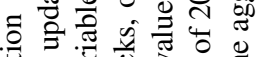

$\Rightarrow$

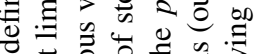

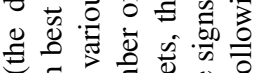

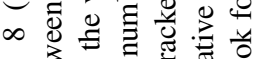

过

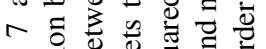

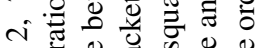

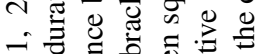

ฉ

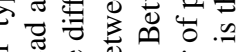

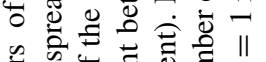

की की चू च्च है।

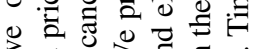

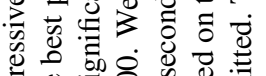

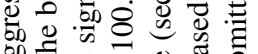

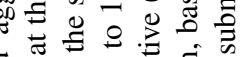

छ

o

is

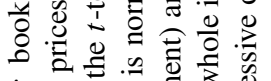

过范

万ั

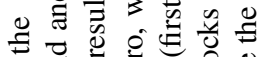

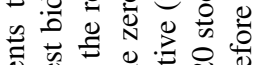

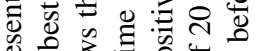

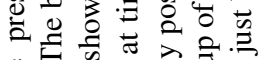

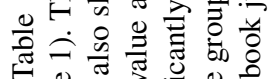

40

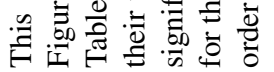

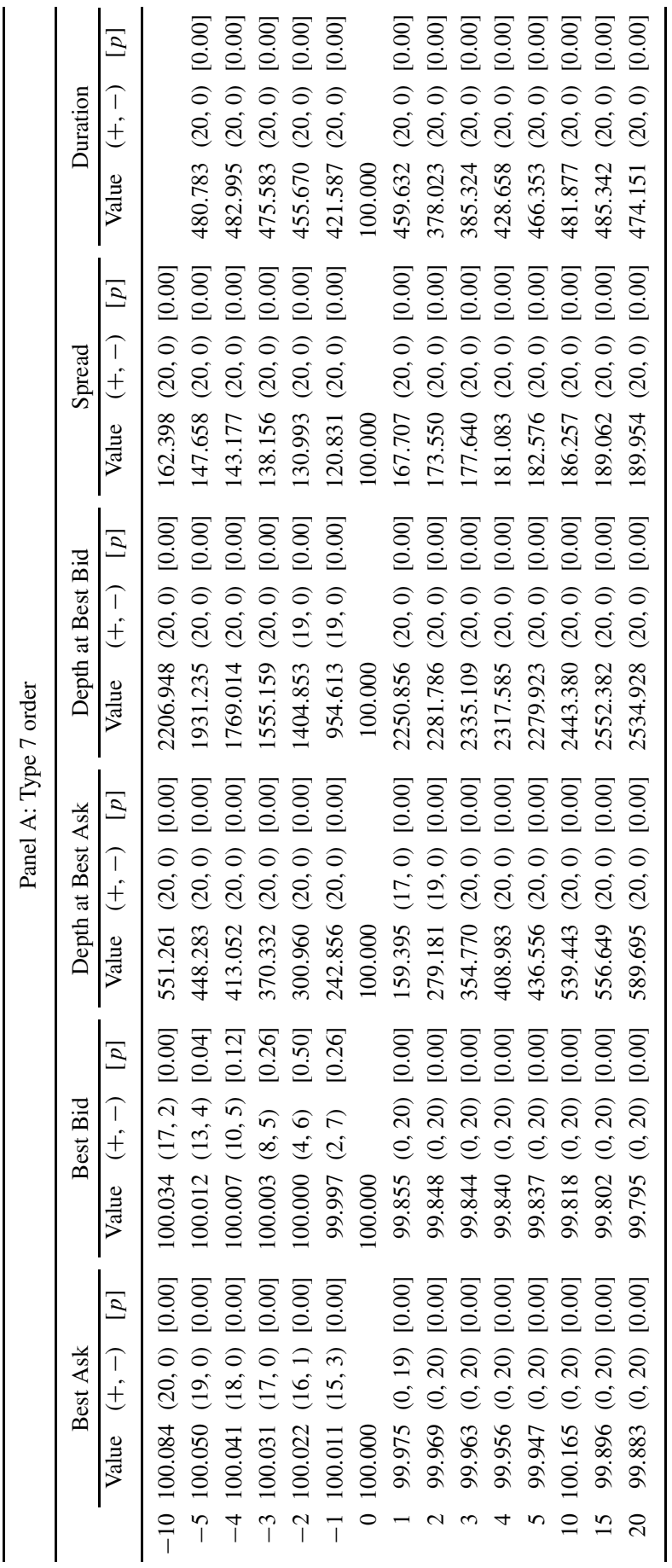




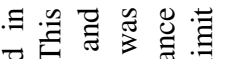

चं क्ते

은

8.500

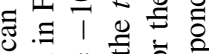

क व्ठㄴ.

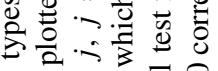

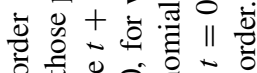

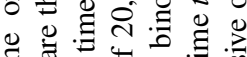

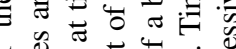

पे

๘

:효

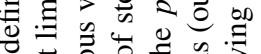

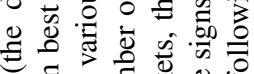

$\infty$ Ð

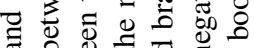

人 5 势

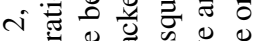

-

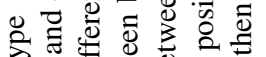

$\exists=$ 의

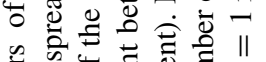

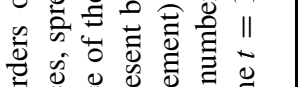

.

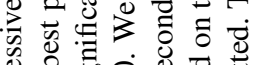

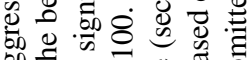

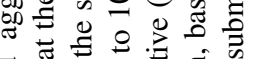

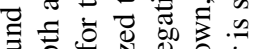

o 웜

की

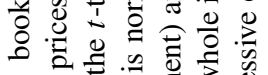

过范

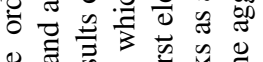

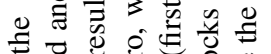

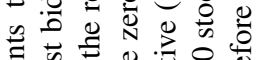

चु

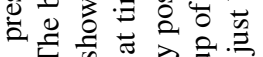

눙

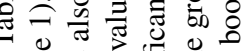

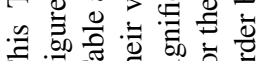

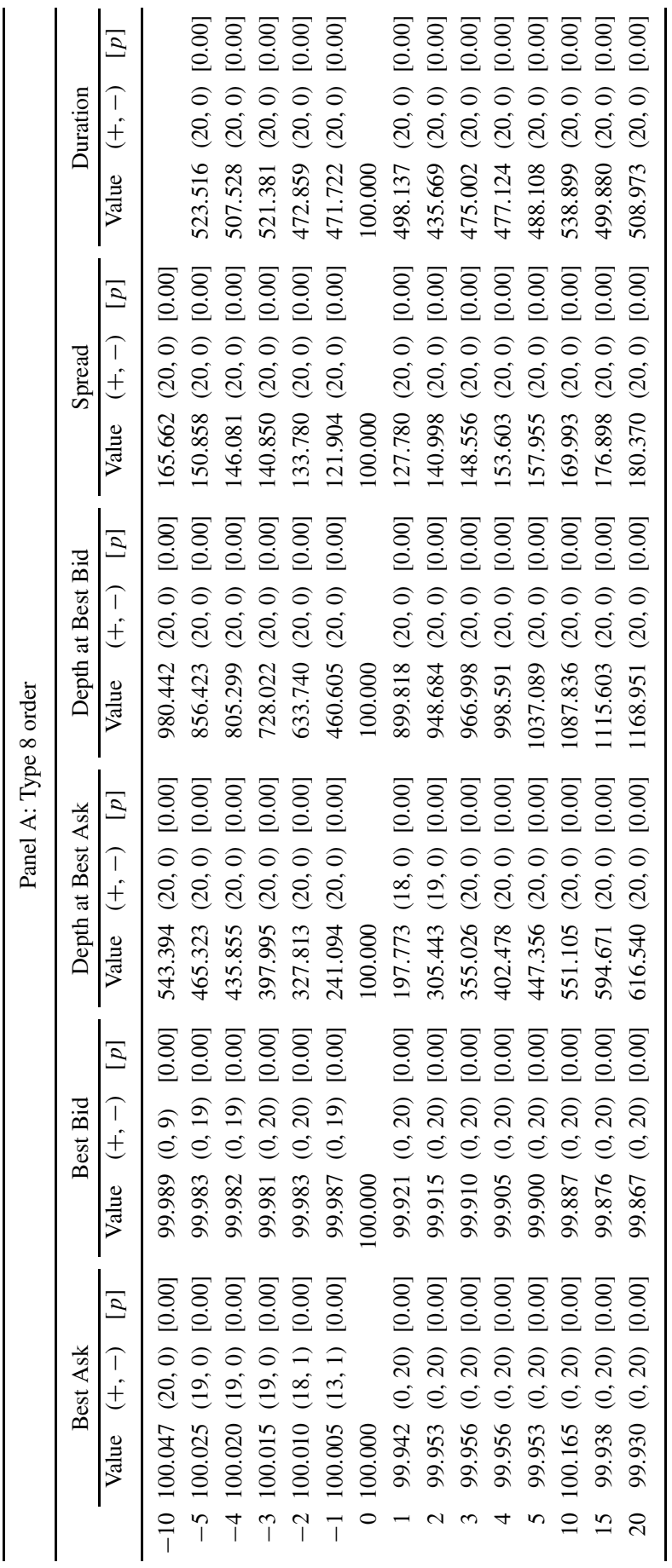


fore, comparing with an average situation may provide additional insights in the resiliency of the market. Again, in each column in Table V, first the value of the variable in period $t=-10, \ldots, 20$ around an aggressive order is shown. Between brackets, the number of stocks with a significant positive and negative difference with respect to the average over time is displayed. This was calculated using a $t$ test. The number of times the test was not significant can then simply be obtained as the difference between twenty and the sum of the numbers between brackets. Between square brackets, we again report the $p$-value of a binomial test of the number of positive $t$-values.

In the different subsections below, we first focus on Figure 3 and Table IV. Then, we compare the results with those implementing the second normalization of which the results are presented in Table V. Since the shape of the patterns is similar across the four groups of stocks, we do not report separate results for the different groups. Nonetheless, when relevant, in each of the subsections below, we will briefly discuss the differences between the groups (results are available from the authors upon request).

\subsubsection{Best Bid and Ask Prices}

We start our discussion of the results by looking at the evolution of the best prices available in the book. As a consequence of the definitions used in the classification of orders, the best ask moves up after the most aggressive buy order. Indeed, we see in Figure 3 that the best ask, given by the dashed line, jumps up after an order of type 1 . The best bid, drawn in full lines, increases as well, but there is no jump. The mirror image is obtained for the most aggressive sell orders: the best bid jumps down, while the ask does not, although the latter decreases as well after the order, but in a more gradual way. An explanation for this was highlighted in section 5.2. There, we documented that a type 1 order (type 7) is likely to be followed by a type 4 (type 10) order, which improves the best bid (ask). Turning to a less aggressive buy order (type 2), we find that the ask price jumps upwards after such order, but now also the bid jumps, but less strongly than the ask. The intuition for the difference in results between the two most aggressive order types is that the unexecuted part of order type 2 pops up at the other side of the market inducing an immediate shift in the bid. After less aggressive sell orders (type 8), the jump in the bid is much smaller and also the subsequent decrease is smaller than after type 7 orders. In all cases however, we find long-run price effects, since neither the best bid nor the best ask return to their levels before the aggressive order. Table 4 shows that for all stocks, best prices in the book are significantly different from their value at the time of the aggressive order during the whole event window after such order.

Note that our measure of price impact is computed in the time window around the aggressive order and thus describes the immediate market impact of the aggressive order. In this way, it differs from the methodology in Griffiths et al. (2000), who use the fill price of an order in their computation of price impact. Given 


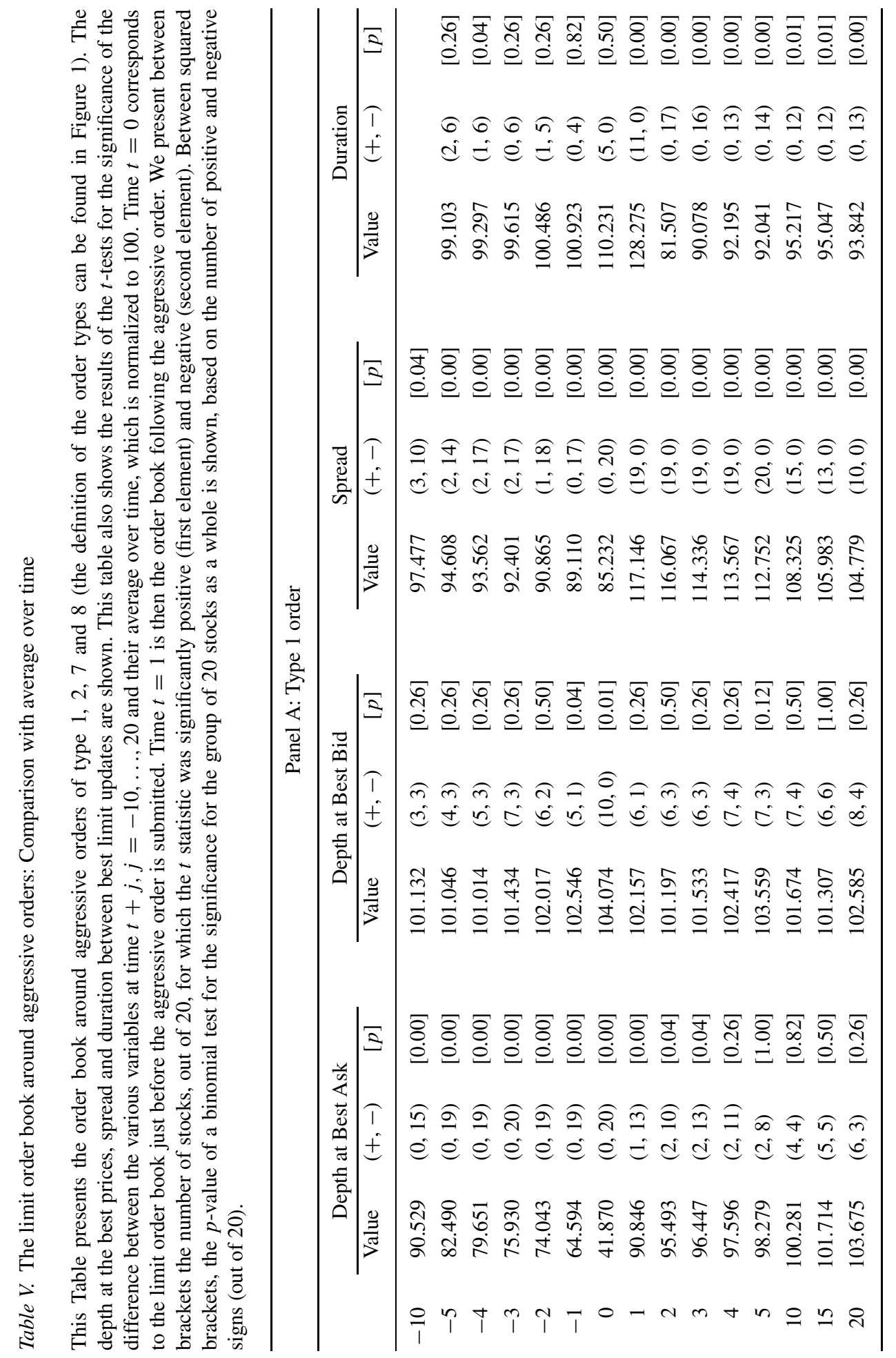




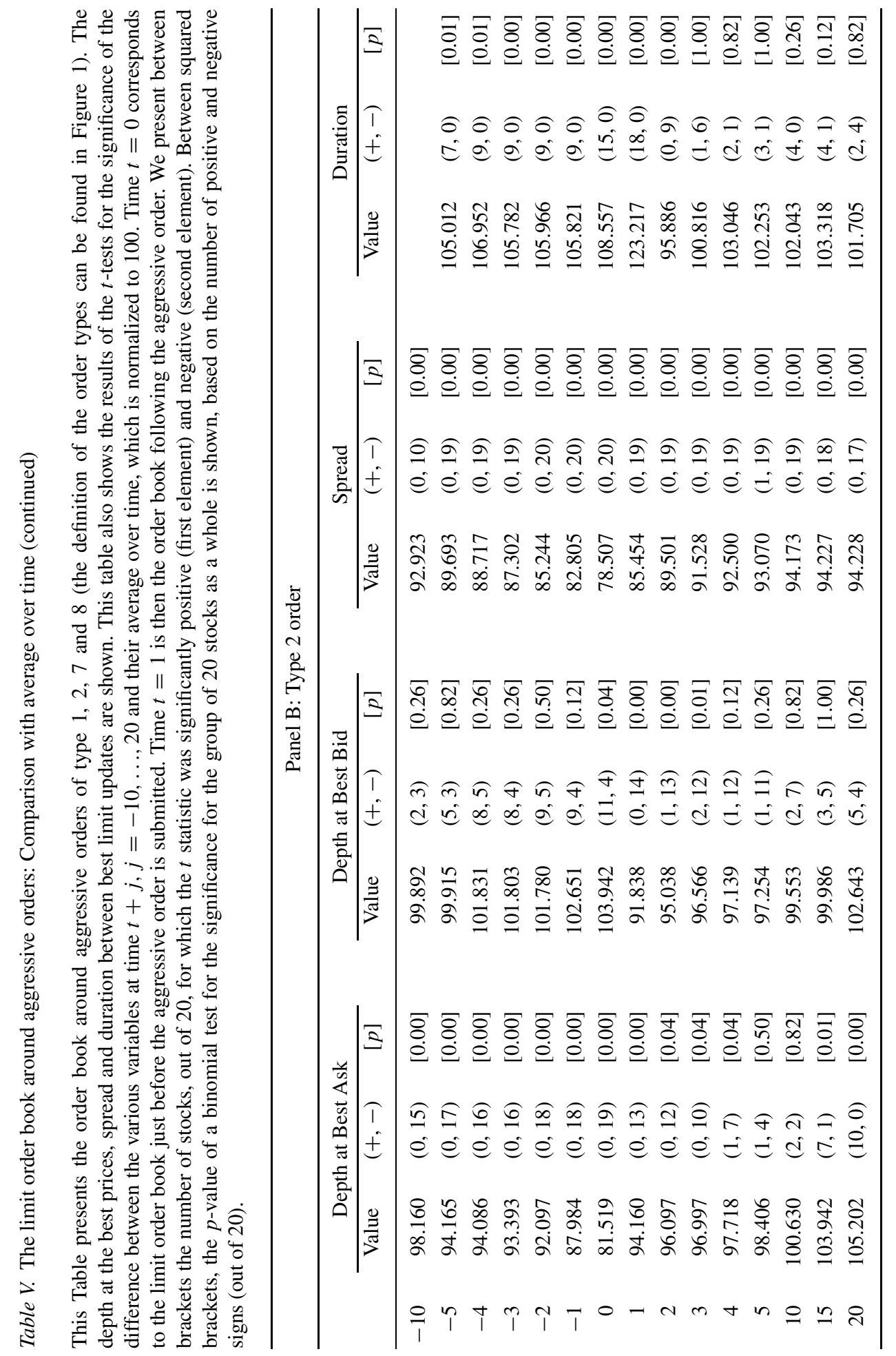




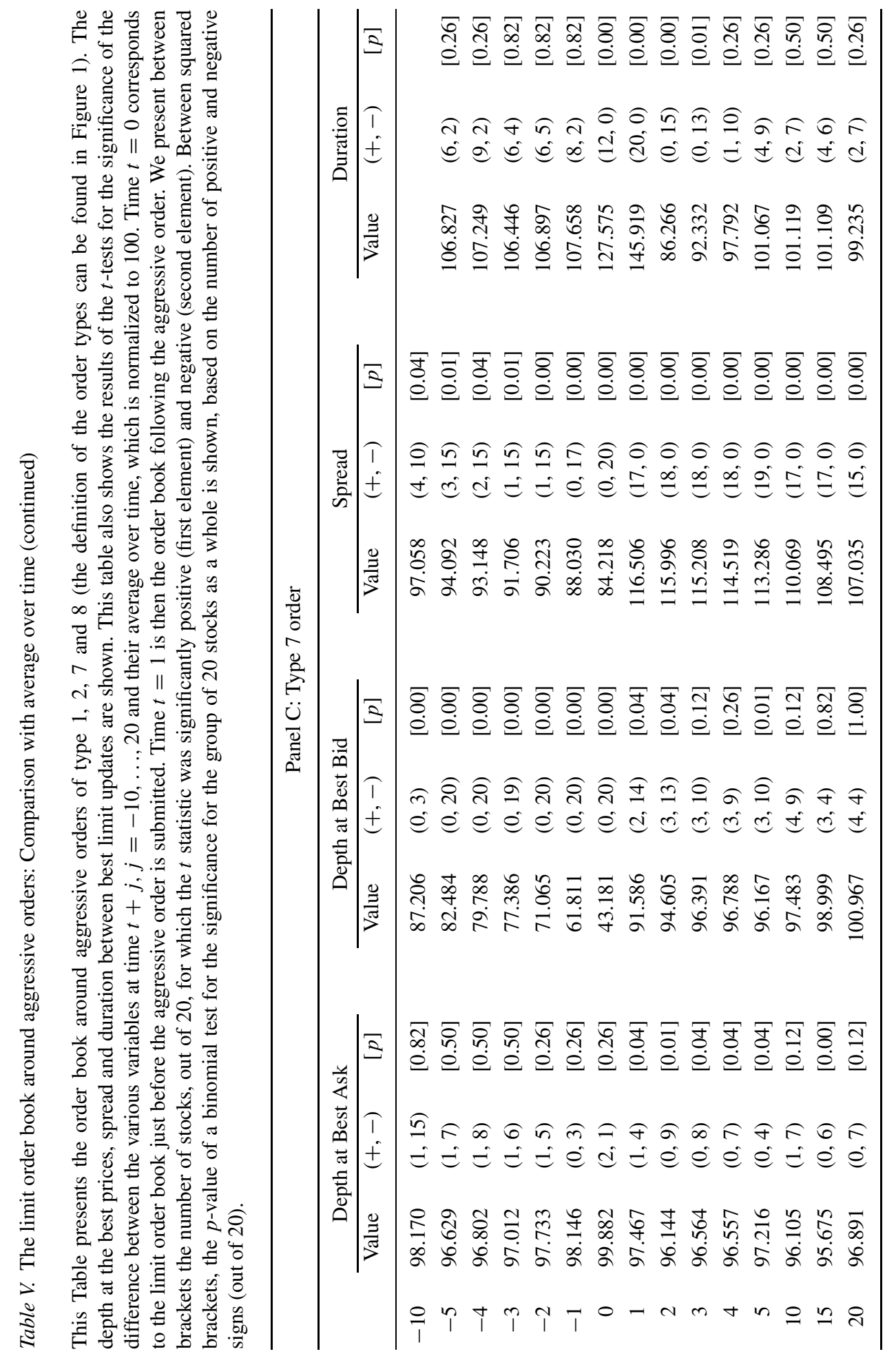




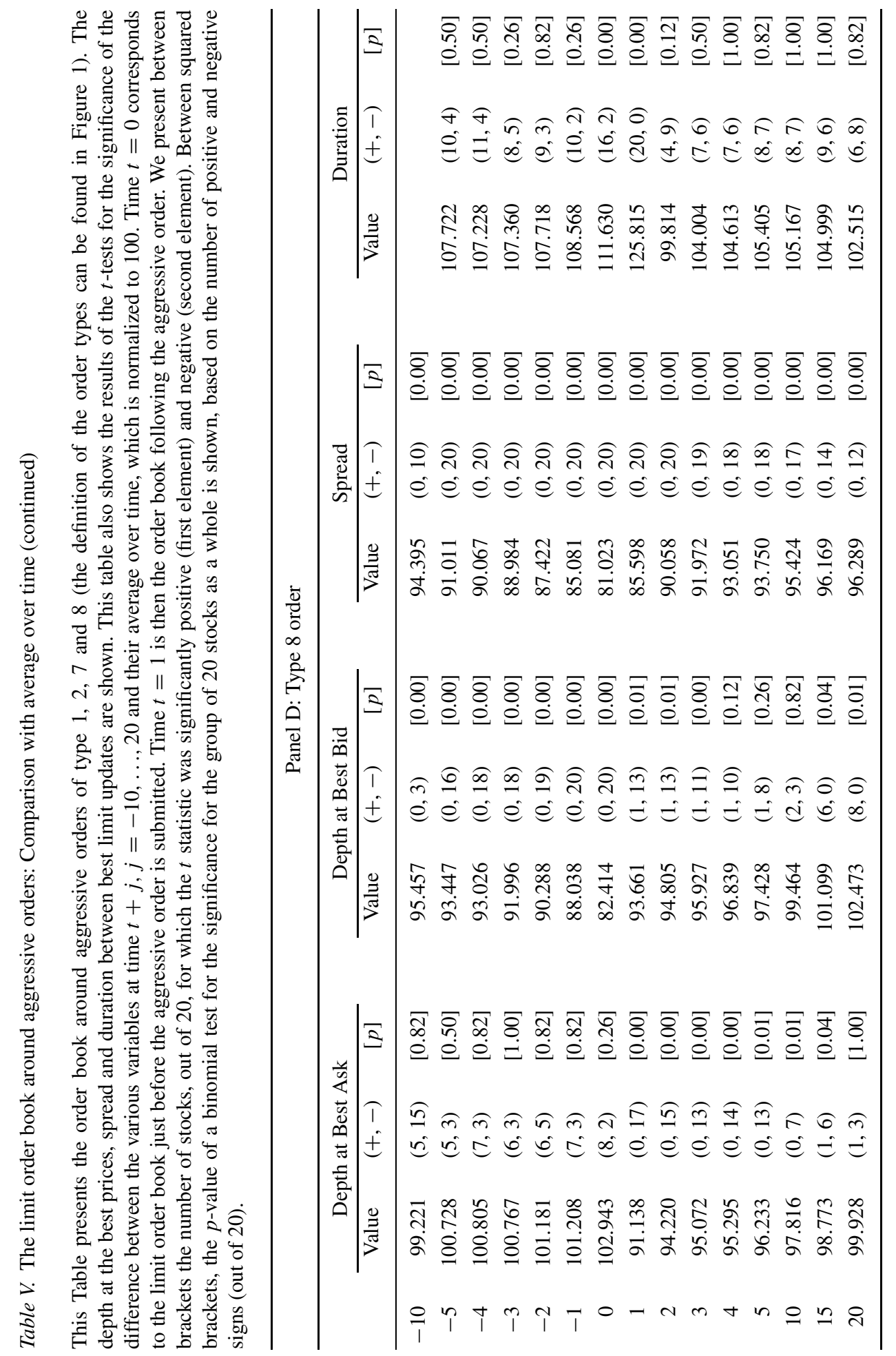


that an order may be filled over time, their measure computes the price impact from the trader's viewpoint, while ours measures the immediate price impact from the market's perspective. The order of magnitude of the price impacts found by Griffiths et al. (2000) is similar, however.

We also briefly discuss the differences between the different groups of stocks. When the best bid and ask change after an aggressive order, the largest effects are found for groups 1 and 2 . These are the small, less frequently traded stocks. This finding holds after both buy and sell orders and after aggressive and less aggressive orders. Moreover, taking the size of the stock as given (thus comparing group 1 with 2, and group 3 with 4), the effect of the most aggressive orders is larger for stocks with a large tick size than for stocks with a small tick size.

\subsubsection{Depth}

Now we turn to the evolution of the depth at the best prices around an aggressive order. These results are shown by the second graphs in the different panels of Figure 3. The depth at the best ask is given by the dashed lines, the depth at the best bid by the solid lines. It can be seen that mainly the depth at the side of the market at which the aggressive order takes place changes. Around an aggressive buy order (type 1) the depth at the best ask decreases before the order and increases sharply afterwards, while the depth at the best bid changes less heavily. Symmetrically, the depth at the best bid decreases before an aggressive sell order (type 7), and increases afterwards. Around less aggressive buy (sell) orders, we find similar patterns, but the changes in the depth at the ask (bid) after a type 2 (type 8 ) order are only about half as large as in the case of the most aggressive buy (sell) order. Furthermore, in both cases the depth at the opposite side of the market also changes after an aggressive order. The reason is that the unfilled part of the type 2 (type 8) order occurs at the other side of the market, in this way influencing the depth at that side. The tests in Table IV show that depth significantly increases after an aggressive order. This evidence has two explanations. The first is that new liquidity is supplied after it has been consumed. An alternative explanation is that the book behind the best bid or ask is deep, and this will show up after a trade that wipes out the volume at the best bid or ask. Similar patterns for depth are reported in an event study by De Winne and D'Hondt (2003).

Using the second normalization, Table $\mathrm{V}$ also shows that the depth at the side of the market at which the aggressive order is submitted, decreases before the order and becomes significantly lower than on average. However, it recovers quickly. Within a few blim updates after such order, there is no clear tendency above or below average and for about half the stocks, the difference with the average depth over time is no longer significant, a result apparent from both the $t$-test and the binomial test. The depth at the other side changes only slightly in the event window and remains closely to its average over time (100). 


\subsubsection{Spread and Duration}

Finally, we investigate if traders who use aggressive orders try to minimize their price impacts by timing their trades. Timing in aggressive order submission can be examined by looking at the spreads and the durations around the submission of the aggressive order. In the third graph in the different panels in Figure 3, the bid-ask spread is drawn, which is defined as the difference between the bid and ask. On average, the spread before an aggressive order decreases. At this point, aggressive orders are submitted quickly, as the average duration between best limit updates is much shorter around an aggressive order. Griffiths et al. (2000) find a positive relation between the bid-ask spread and the aggressiveness of the order but do neither report how much smaller the spread is before its submission nor do they look at durations. After an aggressive order, the spread increases again, not only the next order, but also some orders further into the future. This result stems from the persistence in the order flow (the diagonal effect) highlighted in Section 5.

Again, some points can be made on differences between groups of stocks (results not reported). First, it can be seen that the effect in the periods after an order of type 1 (type 7) is increasing in order aggressiveness: it is stronger than after an order of type 2 (type 8 ). Moreover, the spread stabilizes sooner after a type 1 and 7 order than after a less aggressive order. Secondly, the effect on the spread is decreasing in stock size, i.e. taking tick size as given, it is smaller for the large, frequently traded stocks. Thirdly, the spread changes more for stocks with a smaller tick size. This can be an indication that the larger tick size is a binding constraint. Moreover, we do not find that the speed of convergence towards the competitive spread levels, following an aggressive order, is a function of the tick size, as was predicted by Cordella and Foucault (1999). Fourth, the impact of an aggressive order on duration is decreasing in stock size, meaning the duration after such order is smaller for frequently traded, large stocks.

Table IV investigates the significance of the effects discussed above. For duration and spread, we find that both remain significantly above the pre-aggressive order levels. However, this not necessarily implies that the market is not resilient. Figure 3 shows that the spread 5 to 10 best limit updates before the aggressive order is much higher than at time zero and that after the aggressive order, the spread is still above this level, but far less than compared to the level at time zero. This pattern for the spread is confirmed in De Winne and D'Hondt (2003), although these authors use the relative spread. The pattern is also in line with the findings of Gombert, Schweickert and Theissen (2004) who document a similar spread pattern around large transactions. This finding might indicate, as already mentioned above, that at the event date the spread is rather low, compared to a "normal" situation. Table V reveals similar results. The spread decreases towards the submission of the aggressive order and falls below average. After type 1 and 7 orders, it jumps until above average and then slowly returns, as can be seen from the 
fact that the number of stocks with a statistically significant difference decreases. ${ }^{13}$ The $p$-values of the binomial test clearly confirm this point. For the spread around less aggressive orders (type 2 and 8 ) however, a different pattern emerges. In the whole event window, the spread remains significantly below average. However, also after the type 2 and 8 order spreads slowly return to average. ${ }^{14}$ Finally, the duration before an aggressive order tends to be slightly higher than its average and increases directly after the aggressive order, then sharply decreases and within a few quote updates stabilizes in the neighborhood of its average value over time. The exception is the period after the most aggressive buy order, where duration remains below average for some time.

The results reported in Figure 3 concerning spread and depth show that an aggressive order has permanent effects on both variables relative to the pre-aggressive order level. However, Figure 3 also shows that depth and spread return to a level close to their values $10 \mathrm{blim}$ updates before the aggressive order. If one slightly extends the event window, it is found that that both return to their level 15 to 20 best limit updates before the aggressive order and hence that effects are not permanent. $^{15}$

\subsection{TRANSACTION PRICES AROUND AGGRESSIVE ORDERS}

\subsubsection{Methodology}

Up to now, our discussion considered limit order book variables, such as best prices, depths and spreads. An interesting and complementary issue is the behaviour of transaction prices around aggressive orders. We investigate this issue by creating a window of 30 transactions around the submission of an aggressive order, 10 before and 20 after the aggressive order. The event window analyzed in this subsection differs from the one used when discussing the limit order book, which was defined in terms of best limit price updates. In the current subsection it is specified in terms of transactions. The prices at which transactions take place in this window are denoted by $P_{t}, t=-10, \ldots, 20$. The transaction price at $t=0$ $\left(P_{0}\right)$ is assumed to be the one caused by the aggressive order. Multiple transactions within the same second are aggregated into one transaction, using transaction sizes as weights to compute the average price.

\footnotetext{
13 Also the individual $t$-statistics for the stocks decrease slowly from on average 11.08 just after the type 1 order to 3.23 in period 20.

14 Again, this also appears from the (not reported) individual $t$-statistics of the stocks that decline slowly after a type 2 and 8 order.

15 Extending the event window to 30 orders on the same day before and after the aggressive order reduced the number of observations substantially. Therefore, we do not show these graphs but indicate the qualitative results only.
} 


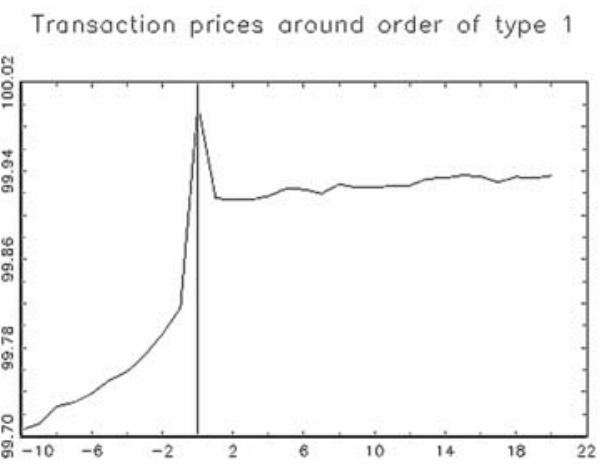

Tronsaction prices around order of type 7

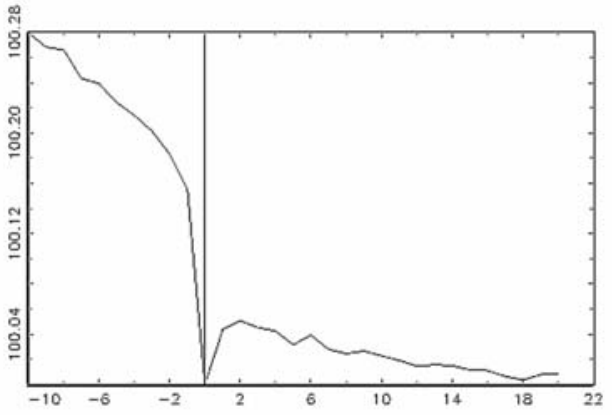

Transaction prices around order of type 2

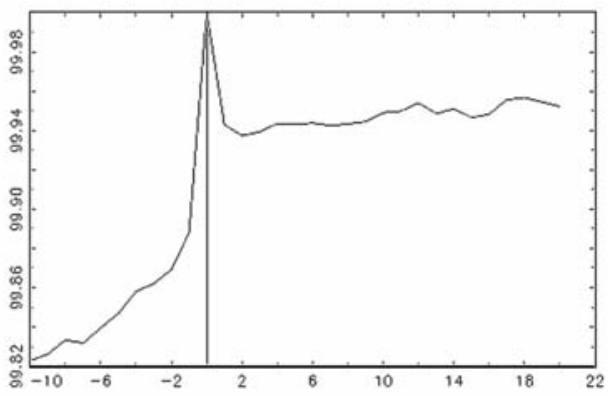

Transoction prices around order of type 8

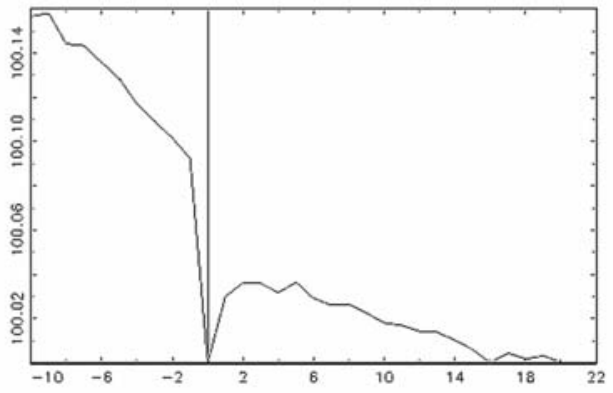

Figure 4. Transaction prices around an aggressive order. This figure presents the prices at which transactions are executed around the submission of aggressive orders of type 1, 2, 7 and 8 at time zero (the definition of the order types can be found in Figure 1). Time $t=0$ corresponds to the transaction caused by the aggressive order. Around the submission, we consider a window of 10 transactions before and 20 transactions after the submission. The values are relative to their value at the time of submission of the order of type 1,2, 7 and 8 respectively, which is set to 100 . In other words, they show how transaction prices change, compared to the time of the aggressive order. Unweighted averages across all stocks are drawn.

\subsubsection{Results}

The evolution of the transaction prices around different types of aggressive orders is presented in Figure 4. The transaction price at $t=0$ is normalized to 100 , all other prices in the event window are relative to this price. Unweighted average values across stocks are reported.

Figure 4 reveals several interesting results. First, transaction prices increase before an aggressive buy order and decrease before an aggressive sell order. At time zero, there is a jump in prices, reflecting the effect of the aggressive order. Secondly, after the aggressive order, the price jump is partly reversed. This reversal is a consequence of the bid-ask bounce. Consider an aggressive order of type 1 occurring at time zero and displayed in the upper left panel of Figure 4 (the reasoning for the other order types is similar). This aggressive order which occurs at the ask leads to an increase in the transaction price at time 0 relative to the 
previous transaction. While by construction, the transaction at time zero is a buyer initiated order, the previous and next transactions, at $t=-1$ and $t=1$, are either buyer initiated (executing at the ask), or seller initiated, transacting at the bid. This bid-ask bounce causes the average price of all transactions following the aggressive order "on average" to revert. However, it is clear that "average" transaction prices remain lower after an aggressive buy order and higher after an aggressive sell order, compared to the event transaction price. This is the long-run price impact that is typically found in market microstructure models, see e.g. Glosten and Milgrom (1985) or Hasbrouck (1991).

To assess the significance of the results in Figure 4, we apply a similar numerical analysis as in the previous sections. Table VI presents the evolution of transaction prices in the event window, where the transaction price is again normalized to 100. The table presents price effects associated with different order types. For each order type, the first column shows how prices change in the interval along the aggressive order. The second column presents the number of stocks for which the difference between the price at $t=0$ and $t=i, i=-10, \ldots, 20$ is significantly positive (first element) or negative (second element). These are computed using a $t$-test. The results in Table VI show that transaction prices do significantly change at $t=0$, when the aggressive order is submitted. In the periods following the aggressive order, transaction prices remain on average significantly lower after type 1 and 2 orders, and higher after type 7 and 8 orders. Although we thus find a long-term effect, prices also show a tendency to return slowly to the transaction price at $t=0$ since the number of stocks for which the difference is significant decreases gradually over time (to 13 or 14 at $t=20$ ). A binomial test based on the number of positive and negative differences at time at $t=0$ and $t=i$, moreover shows that the results are significant for the group of 20 stocks as whole. This is also the case for the average value of the 20th transaction after a type 8 order, which in the table is equal to 100 . Nevertheless, a $t$-test, based on the average transaction prices at $t=20$ of each of the 20 stocks, reveals that the series of these 20 numbers is not significantly different from 100, the event transaction price. This is however due to the one stock whose transaction price is below 100. This price is considerably below 100, while for 13 stocks the price is significantly above, but still relatively close to 100. As a consequence, the average is (almost) 100.

As a final point to Table VI, we investigated the convergence after an aggressive order. Unreported $t$-tests show that the difference between the transaction price at $t=20$ and $t=1$ is significant. In other words, there is a small further correction of prices after the transaction immediately following the aggressive order. Similar $t$-tests reveal that convergence to the new price is achieved within about 10 to 12 transactions since for a majority of the stocks, the difference between $P_{20}$ and $P_{12}$ is not longer significant.

Given the significance of the results, we now analyze the price patterns around aggressive orders in more detail. First, we investigate long-term price effects. We do so by computing the correlation between $P_{t}-P_{-1}$ and $P_{t+5}-P_{t}$. Table VII 
Table VI. Transaction prices: Comparison with aggressive order transaction price

This Table presents transaction prices around aggressive orders of type 1, 2, 7 and 8 (the definition of the order types can be found in Figure 1). For each order type, the first column shows transaction prices in each period, relative to the price at $t=0$, which is normalized at 100 . The second column presents the results of the $t$-tests for the significance of the difference between the various variables at time $t+j, j=-10, \ldots, 20$ and $t=0$. Time $t=0$ corresponds to the transaction caused by the aggressive order. We present between brackets the number of stocks, out of 20 , for which the $t$-statistic was significantly positive (first element) and negative (second element).

\begin{tabular}{|c|c|c|c|c|c|c|c|c|}
\hline & \multicolumn{2}{|c|}{ Type 1 Order } & \multicolumn{2}{|c|}{ Type 2 Order } & \multicolumn{2}{|c|}{ Type 7 Order } & \multicolumn{2}{|c|}{ Type 8 Order } \\
\hline & Value & $(+,-)$ & Value & $(+,-)$ & Value & $(+,-)$ & Value & $(+,-)$ \\
\hline-10 & 99.705 & $(0,20)$ & 99.823 & $(0,12)$ & 100.280 & $(19,0)$ & 100.157 & $(19,0)$ \\
\hline-5 & 99.751 & $(0,20)$ & 99.847 & $(0,20)$ & 100.224 & $(19,1)$ & 100.128 & $(19,1)$ \\
\hline-4 & 99.758 & $(0,20)$ & 99.858 & $(0,20)$ & 100.214 & $(19,1)$ & 100.117 & $(19,1)$ \\
\hline-3 & 99.774 & $(0,20)$ & 99.862 & $(0,20)$ & 100.201 & $(19,1)$ & 100.109 & $(19,1)$ \\
\hline-2 & 99.792 & $(0,20)$ & 99.869 & $(0,20)$ & 100.183 & $(19,1)$ & 100.102 & $(19,1)$ \\
\hline-1 & 99.816 & $(0,20)$ & 99.888 & $(0,20)$ & 100.155 & $(19,1)$ & 100.092 & $(19,1)$ \\
\hline 0 & 100.000 & & 100.000 & & 100.000 & & 100.000 & \\
\hline 1 & 99.915 & $(0,20)$ & 99.943 & $(0,19)$ & 100.044 & $(19,1)$ & 100.030 & $(19,1)$ \\
\hline 2 & 99.914 & $(0,20)$ & 99.937 & $(0,19)$ & 100.051 & $(19,1)$ & 100.036 & $(19,1)$ \\
\hline 3 & 99.914 & $(0,20)$ & 99.939 & $(0,19)$ & 100.045 & $(19,1)$ & 100.036 & $(19,1)$ \\
\hline 4 & 99.917 & $(0,20)$ & 99.943 & $(0,19)$ & 100.043 & $(19,1)$ & 100.032 & $(18,1)$ \\
\hline 5 & 99.924 & $(0,20)$ & 99.943 & $(0,18)$ & 100.032 & $(17,1)$ & 100.036 & $(19,1)$ \\
\hline 10 & 99.925 & $(0,19)$ & 99.949 & $(0,18)$ & 100.023 & $(16,2)$ & 100.018 & $(18,1)$ \\
\hline 15 & 99.936 & $(0,18)$ & 99.946 & $(0,16)$ & 100.012 & $(15,2)$ & 100.006 & $(14,1)$ \\
\hline 20 & 99.936 & $(0,13)$ & 99.952 & $(0,14)$ & 100.008 & $(14,2)$ & 100.000 & $(13,1)$ \\
\hline
\end{tabular}

displays the results. All correlations are negative suggesting a reversal after the aggressive order, in line with the results in Figure 4 and Table VI. In absolute values, the correlations first increase and then decrease over time, confirming the long-run price effect of aggressive orders that showed a tendency for transaction prices to converge slowly to the event transaction price, following an initial partial reversal. ${ }^{16}$ Using (not reported) $t$-tests, we find that all correlations are significant.

\footnotetext{
16 Based on the results in Figure 4, one might expect to find positive correlations between $P_{5}-P_{-1}$ and $P_{10}-P_{5}$, since the figure shows that, for types 1 and 2 (types 7 and 8) price increases (decreases) between transaction -1 and 5 are followed by price increases (decreases). The average correlations in Table VII are however negative. The reasoning is that Figure 4 presents cross-sectional averages over 20 stocks and therefore the bid-ask bounce or other idiosyncratic price movements disappear. These effects induce negative auto-correlation between price changes in small intervals (see e.g. Roll (1984)) and may dominate persistent effects.
} 
Table VII. Long-run correlations between transaction prices around an aggressive order

This table presents long-run correlations, i.e. the correlations between $P_{t+5}-P_{t}$, given by the first column, and $P_{t}-P_{-1}$, given by the second columns in an interval of 20 transactions after an aggressive order of type 1,2, 7 and 8 (the definition of the order types can be found in Figure 1). $P_{t}$ denotes the transaction price of transaction at time $t$. The first row of the table presents the correlation between $P_{1}-P_{0}$ and $P_{0}-P_{-1}$. The subscripts refer to the number of transactions after the aggressive order. Averages across all 20 stocks are shown. Time $t=0$ corresponds to the transaction caused by the aggressive order.

\begin{tabular}{llllll}
\hline & & \multicolumn{4}{c}{ Transaction Prices } \\
\cline { 3 - 6 } & & Type 1 & Type 2 & Type 7 & Type 8 \\
\hline$P_{1}-P_{0}$ & $P_{0}-P_{-1}$ & -0.19 & -0.23 & -0.16 & -0.22 \\
$P_{5}-P_{0}$ & $P_{0}-P_{-1}$ & -0.15 & -0.20 & -0.13 & -0.19 \\
$P_{6}-P_{1}$ & $P_{1}-P_{-1}$ & -0.34 & -0.30 & -0.35 & -0.30 \\
$P_{7}-P_{2}$ & $P_{2}-P_{-1}$ & -0.32 & -0.28 & -0.33 & -0.28 \\
$P_{8}-P_{3}$ & $P_{3}-P_{-1}$ & -0.29 & -0.27 & -0.31 & -0.26 \\
$P_{9}-P_{4}$ & $P_{4}-P_{-1}$ & -0.27 & -0.25 & -0.28 & -0.25 \\
$P_{10}-P_{5}$ & $P_{5}-P_{-1}$ & -0.23 & -0.24 & -0.28 & -0.24 \\
$P_{15}-P_{10}$ & $P_{10}-P_{-1}$ & -0.20 & -0.18 & -0.22 & -0.19 \\
$P_{20}-P_{15}$ & $P_{15}-P_{-1}$ & -0.15 & -0.16 & -0.18 & -0.17 \\
\hline
\end{tabular}

Secondly, we compare long and short-term price effects. Therefore, we consider the price change between time 0 and time $t$ and compare this to the change in prices between time zero and one. Table VIII presents the ratio $\left(P_{t}-P_{0}\right) /\left(P_{1}-P_{0}\right)$. The ratios point to a large initial effect, which is declining subsequently. This decline is more pronounced and rapid after aggressive sell orders than after aggressive buy orders. These ratios quantify the effects displayed in Figure 4 and show more in detail the relative magnitude of the reversal of prices from $t=2$ onwards to the event transaction price.

Finally, we compare the change in transaction prices between time 0 and time 20 with the spread prevailing just before the aggressive order by computing the ratio $\left(P_{20}-P_{0}\right) /\left(\right.$ Spread $\left._{0}\right)$. For a type 1 transaction, this ratio is $-16 \%$. This means that $32 \%$ of the half-spread is reversed and $68 \%$ is a permanent information effect. For the other types the permanent effects are 78\% (type 2), 80\% (type 7) and 86\% (type 8). It seems somewhat surprising that the permanent effect is larger (in percentage terms) for the less aggressive transaction types, but notice that these have a smaller initial effect as these do not move the best bid or ask quote. These results can be compared to de Jong, Nijman and Roell (1996), who do not distinguish between aggressive and less aggressive trades but rather look at trade size. They find a permanent price impact of a small trade of $50 \%$ of the bid-ask spread, whereas the impact of a very large trade is around $100 \%$ of the spread. 
Table VIII. Short and long term effects of aggressive orders on transaction prices

This table presents the ratio $\left(P_{t}-P_{0}\right) /\left(P_{1}-P_{0}\right)$ in an interval of 20 transactions after an aggressive order of type 1,2, 7 and 8 (the definition of the order types can be found in Figure 1). Time $t=0$ corresponds to the transaction caused by the aggressive order. The subscript thus refers to the number of transactions after the aggressive order. Averages across all 20 stocks are shown.

\begin{tabular}{lcccc}
\hline & \multicolumn{4}{c}{ Transaction Prices } \\
\cline { 2 - 5 } & Type 1 & Type 2 & Type 7 & Type 8 \\
\hline$\left(P_{2}-P_{0}\right) /\left(P_{1}-P_{0}\right)$ & 1.04 & 1.08 & 1.00 & 1.16 \\
$\left(P_{3}-P_{0}\right) /\left(P_{1}-P_{0}\right)$ & 1.03 & 1.07 & 1.03 & 1.11 \\
$\left(P_{4}-P_{0}\right) /\left(P_{1}-P_{0}\right)$ & 0.96 & 1.06 & 0.94 & 1.06 \\
$\left(P_{5}-P_{0}\right) /\left(P_{1}-P_{0}\right)$ & 0.92 & 0.98 & 0.88 & 1.05 \\
$\left(P_{6}-P_{0}\right) /\left(P_{1}-P_{0}\right)$ & 0.91 & 0.98 & 0.84 & 1.00 \\
$\left(P_{7}-P_{0}\right) /\left(P_{1}-P_{0}\right)$ & 0.91 & 0.96 & 0.76 & 0.97 \\
$\left(P_{8}-P_{0}\right) /\left(P_{1}-P_{0}\right)$ & 0.86 & 0.96 & 0.72 & 0.94 \\
$\left(P_{9}-P_{0}\right) /\left(P_{1}-P_{0}\right)$ & 0.82 & 0.95 & 0.70 & 0.87 \\
$\left(P_{10}-P_{0}\right) /\left(P_{1}-P_{0}\right)$ & 0.83 & 0.89 & 0.63 & 0.83 \\
$\left(P_{11}-P_{0}\right) /\left(P_{1}-P_{0}\right)$ & 0.82 & 0.84 & 0.63 & 0.77 \\
$\left(P_{12}-P_{0}\right) /\left(P_{1}-P_{0}\right)$ & 0.79 & 0.78 & 0.60 & 0.72 \\
$\left(P_{13}-P_{0}\right) /\left(P_{1}-P_{0}\right)$ & 0.75 & 0.85 & 0.56 & 0.73 \\
$\left(P_{14}-P_{0}\right) /\left(P_{1}-P_{0}\right)$ & 0.74 & 0.82 & 0.55 & 0.67 \\
$\left(P_{15}-P_{0}\right) /\left(P_{1}-P_{0}\right)$ & 0.72 & 0.87 & 0.58 & 0.57 \\
$\left(P_{16}-P_{0}\right) /\left(P_{1}-P_{0}\right)$ & 0.71 & 0.83 & 0.49 & 0.61 \\
$\left(P_{17}-P_{0}\right) /\left(P_{1}-P_{0}\right)$ & 0.75 & 0.73 & 0.48 & 0.56 \\
$\left(P_{18}-P_{0}\right) /\left(P_{1}-P_{0}\right)$ & 0.71 & 0.73 & 0.50 & 0.54 \\
$\left(P_{19}-P_{0}\right) /\left(P_{1}-P_{0}\right)$ & 0.70 & 0.75 & 0.51 & 0.51 \\
$\left(P_{20}-P_{0}\right) /\left(P_{1}-P_{0}\right)$ & 0.68 & 0.77 & 0.53 & 0.50 \\
\hline
\end{tabular}

\section{Conclusion}

Limit order markets are gaining importance as trading mechanism of financial markets. We analyzed the resiliency of a pure limit order market (the Paris Bourse) by examining order flow behavior around aggressive orders (large orders that move prices). Limit order markets, in contrast to dealership markets, do not have market makers to provide resiliency. Market resiliency is essential for the risk management of large institutional investors when handling their order flow. It also determines the cost of capital of quoted companies.

The main findings of the paper can be summarized as follows. First, the diagonal effect, i.e. serial correlation in the order flow, as reported by Biais, Hillion and Spatt (1995) is found to be persistent even after one order. It takes about 50 subsequent 
orders before the order flow returns to its unconditional pattern. The persistency in the diagonal effect also holds for the most aggressive orders. Secondly, we discover that spreads and depth decline in the run-up to an aggressive order, and that best prices, depth, spread and duration remain significantly larger than their respective values at the time of submission of the aggressive order. Except for bid and ask prices, where a long-run effect is found, all variables in the limit order book do return to their initial level within around 20 best limit updates after the aggressive order. However, and this is our third point, we have indications that the limit order book around an aggressive order differs from the "average" book over time since the depth and spread are rather small just before the aggressive order. Therefore, we also compared the evolution of the different variables with respect to their average values over time. These results show that the market is quite resilient. Especially when considering the depth at the best prices, we find that after an aggressive order, depth recovers within a few quote updates and returns to average. Also the spread returns to its average, but this occurs more slowly. Fourthly, our analysis of an event window of transaction prices around aggressive orders reveals that there are longterm effects of aggressive orders on transaction prices. The "average" transaction prices after an aggressive buy order (sell order) are higher (lower) than the preevent transaction price. Finally, we find that both firm size and tick size contribute to the variation of the impact in order aggressiveness.

\section{References}

Ahn, H., Cao, C., and Choe, H. (1998) Decimalization and competition among stock markets: Evidence from the Toronto stock exchange cross-listed securities, Journal of Financial Markets $\mathbf{1}$, 51-87.

Angel, J. (1997) Tick size, share prices, and stock splits, Journal of Finance 52, 655-681.

Bacidore, J. (1997) The impact of decimalization on market quality: An empirical investigation of the Toronto stock exchange, Journal of Financial Intermediation 6, 92-120.

Bhattacharya, U. and Spiegel, M. (1998) Anatomy of a market failure: NYSE trading suspensions (1974-1988), Journal of Business \& Economic Statistics 16, 216-226.

Biais, B., Glosten, L., and Spatt, C. (2002) The microstructure of stock markets, CEPR discussion paper 3288.

Biais, B., Hillion, P., and Spatt, C. (1995) An empirical analysis of the limit order book and the order flow in the Paris Bourse, Journal of Finance 50, 1655-1689.

Biais, B., Hillion, P., and Spatt, C. (1999) Price discovery and learning during the pre-opening period in the Paris Bourse, Journal of Political Economy 107, 1218-1248.

Bisière, C. and Kamionka, T. (2000), Timing of orders, orders aggressiveness and the order book in the Paris Bourse, Annales D'Economie et de Statistique 60, 43-72.

Bourghelle D. and Declerck, F. (2004) Why markets should not necessarily reduce tick size, Journal of Banking and Finance 28, 373-398.

Chordia, T., Roll, R., and Subrahmanyam, A. (2001) Market liquidity and trading activity, Journal of Finance 49, 255-267.

Cohen, K., Maier, S., Schwartz, R., and Whitcomb, D. (1981) Transaction costs, order placement strategy and existence of the bid-ask spread, Journal of Political Economy 89, 287-305.

Coppejans, M., Domowitz, I., and Madhavan, A. (2003) Resiliency in an automated auction, Unpublished working paper. Barclays Global Investors, ITG Inc. 
Cordella, T. and Foucault, T. (1999) Minimum price variations, time priority, and quote dynamics, Journal of Financial Intermediation 8, 141-173.

D'Hondt, C., De Winne, R., and François-Heude, A. (2002) Market liquidity on eurnonext Paris: Nothing is quite as it seems, Unpublished working paper, FUCaM.

De Winne, R. and D'Hondt, C. (2003) Rebuilding the limit order book on euronext or how to improve market liquidity assessment, Unpublished working paper, FUCaM.

de Jong, F., Nijman, T., and Roell, A. (1995) A comparison of the cost of trading French shares on the Paris Bourse and on SEAQ international, European Economic Review 39, 1277-1301.

de Jong, F., T. Nijman, and Roell, A. (1996) Price effects of trading and components of the bid-ask spread on the Paris Bourse, Journal of Empirical Finance 3, 193-213.

Domowitz, I. and Steil, B. (1999) Automation, trading costs, and the structure of the securities trading industry, Brookings-Wharton Papers on Financial Services, 33-92.

Easley, D., Kiefer, N., and O'Hara, M. (1997) One day in the life of a very common stock, Review of Financial Studies 10, 805-835.

Foucault, T. (1999) Order flow composition and trading costs in a dynamic limit order market, Journal of Financial Markets 2, 99-134.

Foucault, T., Kadan, O., and Kandel, E. (2003) Limit order book as a market for liquidity, Forthcoming in Review of Financial Studies.

Glosten, L. and Milgrom, P. (1985) Bid, ask and transaction prices in a specialist market with heterogeneously informed traders, Journal of Financial Economics 14, 71-100.

Glosten, L. and Harris, L. (1988) Estimating the components of the bid-ask spread, Journal of Financial Economics 21, 123-142.

Goldstein, M. and Kavajecz, K. (2000) Eights, sixteenths, and market depth: Changes in tick size on liquidity provision on the NYSE, Journal of Financial Economics 56, 125-149.

Gomber, P., Schweickert, U., and Theissen, E. (2004) Zooming in on liquidity, Unpublished working paper, University of Bonn.

Griffiths, M., Smith, B., Turnbull, D., and White, R. (1998) The tole of tick size in upstairs trading and downstairs trading, Journal of Financial Intermediation 7, 393-417.

Griffiths, M., Smith, B., Turnbull, D., and White, R. (2000) The costs and determinants of order aggressiveness, Journal of Financial Economics 56, 65-88.

Harris, L. (1990) Liquidity, trading rules and electronic trading systems, NYU Salomon Center Series in Finance and Economics, Monograph 1990-1994.

Hasbrouck, J. (1991) The summary informativeness of stock trades: An econometric analysis, Review of Financial Studies 4, 571-595.

Hasbrouck, J. (1995) One security, many markets: Determining the contributions to price discovery, Journal of Finance 50, 1175-1199.

Hedvall, K. and Niemeyer, J. (1997) Order flow dynamics: Evidence from the Helsinki stock exchange, Unpublished working paper, Swedish School of Economics and Business Administration.

Hollifield, B., Miller, R., and Sandas, P. (2004) Empirical analysis of limit order markets, Review of Economic Studies 71, 1024-1063.

Hollifield, B., Miller, R., Sandas, P., and Slive, J. (2003) Liquidity supply and demand: Empirical evidence from the Vancouver stock exchange, Unpublished working paper GSIA, Carnegie Mellon University.

Jain, P. (2002), Institutional design and liquidity on stock exchanges, Unpublished working paper, Indiana University.

Madhavan, A. (2000) Market microstructure: A survey, Journal of Financial Markets 3, 205-258.

McInish, T. and Wood, R. (1992) An analysis of intraday patterns in bid/ask spreads for NYSE stocks, Journal of Finance 47, 753-764.

Parlour, C. (1998) Price dynamics in limit order markets, Review of Financial Studies 11, 789-816. 
Roll, R. (1984) A simple implicit measure of the effective bis-ask spread in an efficient market, Journal of Finance 39, 1127-1139.

Seppi, D. (1997) Liquidity provision with limit orders and a strategic specialist, Review of Financial Studies 10, 103-150.

Stigler, R. (1964) Public regulation of the securities markets, Journal of Business 37, 117-142. 